\title{
Src-dependent NM2A tyrosine-phosphorylation regulates actomyosin dynamics
} Cláudia Brito ${ }^{1,2,3}$, Francisco S. Mesquita ${ }^{1,2, \S, \#}$, Daniel S. Osório ${ }^{1,2, \S}$, Joana Pereira ${ }^{1,2,3}$, Neil
Billington $^{4}$, James R. Sellers ${ }^{4}$, Didier Cabanes ${ }^{1,2, \$}$, Ana X. Carvalho ${ }^{1,2, \$}$ and Sandra Sousa ${ }^{1,2, \star}$

${ }^{1}$ i3S-Instituto de Investigação e Inovação em Saúde, Universidade do Porto, Portugal; ${ }^{2}$ IBMC, Instituto de Biologia Celular e Molecular; ${ }^{3}$ MCBiology PhD Program - ICBAS, University of Porto, Portugal; ${ }^{4}$ Cell and Developmental Biology Center, National Heart Lung and Blood Institute, NIH, Bethesda, MD, USA \#present address: Global Health Institute, School of Life Sciences, École Polytechnique Fédérale de Lausanne, Lausanne, Switzerland;

${ }^{\S}$ These authors shared the second authorship.

${ }^{\$}$ These authors shared the second last authorship.

*corresponding author: srsousa@ibmc.up.pt 


\begin{abstract}
Non-muscle myosin 2A (NM2A) is a key cytoskeletal enzyme that along with actin assembles into actomyosin filaments inside cells. NM2A is fundamental in cellular processes requiring force generation such as cell adhesion, motility and cell division, and plays important functions in different stages of development and during the progression of viral and bacterial infections. We previously identified at the motor domain of the NM2A, a novel Src-dependent tyrosine phosphorylation on residue $158\left(\mathrm{pTyr}^{158}\right.$ ), which is promoted by Listeria monocytogenes infection. Despite the central role of NM2A in several cell biology processes, the pTyr at this specific residue had never been reported. Here we showed that LLO, a toxin secreted by Listeria, is sufficient to trigger NM2A pTyr ${ }^{158}$ by activating Src, which coordinates actomyosin remodeling. We further addressed the role of NM2A pTyr ${ }^{158}$ on the organization and dynamics of the actomyosin cytoskeleton and found that by controlling the activation of the NM2A, the status of the pTyr ${ }^{158}$ alters cytoskeletal organization, dynamics of focal adhesions and cell motility, without affecting NM2A enzymatic activity in vitro. Ultimately, by using Caenorhabditis elegans as a model to assess the role of this $\mathrm{pTyr}^{158}$ in vivo, we found that the status of the $\mathrm{pTyr}^{158}$ has implications in gonad function and is required for organism survival under stress conditions. We conclude that the fine control of the NM2A pTyr ${ }^{158}$ is required for cell cytoskeletal remodeling and dynamics, and we propose Src-dependent NM2A pTyr ${ }^{158}$ as a novel layer of regulation of the actomyosin cytoskeleton.
\end{abstract}

\title{
Key words
}

NM2A, Src activation, actomyosin cytoskeleton, cytoskeletal organization, LLO intoxication, NMY-2, C. elegans. 


\section{Abbreviations}

ATP - Adenosine tri-phosphate

$\mathrm{CA}$ - Constitutively active

CFP - Cyan Fluorescence Protein

CTR - Control

C. elegans - Caenorhabditis elegans

DAPI - 4',6-diamidino-2-phenylindole dihydrochloride

Dasa - Dasatinib

DMSO - Dimethyl Sulfoxide

DTT - Dithiothreitol

ELC - Essential light chain

EGTA - Egtazic acid

FAs - Focal adhesions

FRAP - Fluorescence recovery after photobleaching

FRET - Fluorescence resonance energy transfer

Glu - Glutamate

HMM - Heavy meromyosin

IPTG - Isopropyl- $\square$-D-thiogalactopyranoside

KD - Kinase dead

LLO - Listeriolysin O

MFI - Mean Fluorescence Intensity

MLCK - Myosin light chain kinase

$\mathrm{MOI}$ - Multiplicity of infection

MOPS - 3-(N-morpholino)propanesulfonic acid

NGM - Nematode growth medium

$\mathrm{NI}$ - Non-intoxicated

NM2A - Non-muscle myosin 2A

NMHC2A - Non-muscle heavy chain myosin 2A

Phe - Phenylalanine

PFT - Pore-forming toxin

$\mathrm{PI}$ - Propidium lodide

PM - Plasma membrane

PMSF - Phenylmethylsulfonyl Fluoride

pTyr - Tyrosine phosphorylation or tyrosine-phosphorylated

pTyr ${ }^{158}$ - Phosphorylation of tyrosine 158

RLC - Regulatory light chain

RNAi - Ribonucleic acid interference 
bioRxiv preprint doi: https://doi.org/10.1101/2020.08.12.246090; this version posted August 13, 2020. The copyright holder for this preprint (which was not certified by peer review) is the author/funder. All rights reserved. No reuse allowed without permission.

\section{Tyr $^{419}$ - Tyrosine 419 \\ $\mathrm{Tyr}^{530}$ - Tyrosine 530 \\ WCL - Whole cell lysate \\ Ypet - Yellow pet}




\section{Introduction}

The non-muscle myosin 2A (NM2A) is a major cytoskeletal enzyme that plays a central role on contraction of the actin cytoskeleton [1]. Each NM2A molecule is a hexameric complex composed by two non-muscle myosin heavy chains (NMHC2As) and two pairs of light chains: the regulatory (RLCs) and essential (ELCs) light chains [2]. NMHC2A folds into three different domains: the conserved head/motor domain comprising the sites for ATP hydrolysis and actin binding; the neck domain that interacts with the light chains, stabilizing the protein and regulating NM2A activity; and the tail containing a coiled-coil region responsible for heavy chain homodimerization and NM2 filament formation [2, 3]. Phosphorylation of the RLCs at serine 19 regulates the enzymatic activity of NM2A and its filament formation. The inactive form of NM2A with unphosphorylated RLCs folds into a compact structure in which motor heads and tails directly interact. This autoinhibited molecule does not form filaments, interacts only weakly with actin and freely diffuses in cells. Upon phosphorylation of the RLC, active NM2A molecules undergo antiparallel self-association to form bipolar filaments [4, 5], the NM2A work unit in cells. Bipolar filaments interact with actin bundles, assemble into actomyosin filaments and power actin contraction [6] by converting chemical energy into mechanical force via ATP hydrolysis [7]. NM2A filament assembly and their subcellular distribution are also regulated by a specific phosphorylation on RLC tyrosine 155 in migrating cells [8], on serine and threonine residues at the NMHC2A tail domain $[9,10]$ and by interactions with cytosolic chaperones, such as HSP90, UNC-45A and UNC-45B [11-13].

$\mathrm{NM} 2 \mathrm{~A}$ is broadly required for processes dependent on force generation and remodeling of the actomyosin cytoskeleton [6, 14]. Defects on NM2A function are associated with a multitude of human diseases [15-17] including various viral and bacterial infections [18]. Upon cellular infection by the human pathogen Listeria monocytogenes, Src kinase is activated [19] and NMHC2A is tyrosine-phosphorylated on its motor head, in a Src-dependent manner [20]. This NMHC2A phosphorylation occurs at the highly conserved residue tyrosine $158\left(\mathrm{Tyr}^{158}\right)$ and plays a restrictive role in bacterial cellular invasion [20]. During infection, NM2A is also involved in host cellular responses to plasma membrane (PM) damage induced by bacterial pore-forming toxins (PFTs) [21-24]. Upon intoxication, NM2A coordinates actomyosin cytoskeleton reorganization, cellular blebbing and lysosomal secretion, which are required for membrane repair $[21,23,25]$.

Here we investigated if the remodeling of NM2A caused by PFTs correlates with NMHC2A tyrosine phosphorylation (pTyr) triggered by pathogens during cellular infection [20]. In addition, we assessed the impact of NMHC2A pTyr ${ }^{158}$ on myosin activity, dynamics, cell adhesion and migration. We found that, although the phosphorylation status of $\mathrm{Tyr}^{158}$ does not interfere with the mechanical and motor properties of NM2A in vitro, a Src-dependent tight regulation of the $\mathrm{pTyr}^{158}$ is essential for the proper organization of the actomyosin cytoskeleton. The 
phosphorylation status of $\mathrm{Tyr}^{158}$ modifies cytoskeletal organization, focal adhesion assembly/disassembly and cell motility parameters. In Caenorhabditis elegans we observed that CRISPR/Cas-9-modified animals expressing the phosphomimetic (Y163E) version of NMY-2, the major non-muscle myosin-2 in this system, are sterile and display impaired gonad function, whereas animals carrying the non-phosphorylatable mutation (Y163F) are more susceptible to stress and to intoxication. 


\section{Results}

\section{LLO intoxication induces NMHC2A pTyr through Src activation}

Given that Listeria infection triggers the Src-dependent $\mathrm{pTyr}^{158}$ of NMHC2A [20] and that its PFT Listeriolysin O (LLO) promotes the remodeling of NM2A cytoskeleton [21, 22], we investigated if LLO by itself is sufficient to activate Src kinase and trigger NMHC2A pTyr. Total pTyr proteins were immunoprecipitated (IP), using an anti-pTyr antibody, from lysates of HeLa cells in control conditions (non-intoxicated, NI) or after incubation with purified LLO. While the levels of NMHC2A in whole cells lysates (WCL) were comparable in NI and LLO-intoxicated samples, NMHC2A was significantly enriched in pTyr IP fractions from LLO-intoxicated cells (Fig 1A, B). This, together with our previous data [20], indicates that LLO is sufficient to trigger NMHC2A pTyr. To assess if LLO-induced NMHC2A pTyr correlates with the activation of Src kinase, we evaluated the levels of activated Src in non-intoxicated (NI) or LLO-intoxicated HeLa cells. The full activation of $\mathrm{Src}$ requires both dephosphorylation on tyrosine $530\left(\mathrm{Tyr}^{530}\right)$ and phosphorylation on tyrosine $419\left(\mathrm{Tyr}^{419}\right)$ [26, 27], that can be specifically detected by immunoblot. Levels of full active Src (Src pTyr ${ }^{419}$ ) transiently increased upon LLO-intoxication of HeLa cells (Fig 1C, D). In agreement, the amount of active Src, detected by the dephosphorylation of Tyr ${ }^{300}$ also increased in response to LLO (Fig S1A, B). To confirm that LLO is sufficient to trigger Src activation and examine the distribution of active Src at the single cell level, we performed confocal microscopy using the specific FRET-based ECFP/YPet Src biosensor [28]. The ratio of CFP/YPet signals, indicating active/inactive Src, remained constant throughout time in NI conditions (Fig 1E, F) (Movie M1). Upon LLO intoxication the CFP/YPet ratio showed a consistent increase that is sustained overtime (Fig 1E, F), reflecting global Src activation in LLO-intoxicated cells. At some distinct regions, we detected stronger signal associated to LLO-induced plasma membrane (PM) blebs (Fig 1E, arrows), which suggests higher Src activation in places where the cell was responding to LLO-induced PM damage. Concurrently, confocal microscopy analysis of $\mathrm{NI}$ and LLO-intoxicated HeLa cells showed that active Src mainly localized at the perinuclear region in NI cells, but upon LLO intoxication was detected at the cell cortex within the previously described toxin-induced NM2A-enriched cortical bundles [21, 23] (Fig 1G). This indicates that Src activity might be required at the cell periphery possibly to regulate cytoskeleton responses against LLO-induced PM damage. In addition, these data suggest that LLO is sufficient to activate Src, which in turn controls NMHC2A pTyr as it occurs during Listeria infection [20].

To determine if Src activity is necessary for NMHC2A pTyr mediated by LLO intoxication, we interfered with Src activity by: 1) using the pharmacological inhibitor Dasatinib (Dasa, Fig 1H), 2) downregulating Src expression through specific shRNAs (shSrc, Fig 1J), and 3) overexpressing Src kinase mutants (Fig 1L). Levels of NMHC2A were assessed in IP pTyr fractions obtained from cells intoxicated with LLO in control or Src inactivated conditions. In control conditions, 
LLO consistently induced an enrichment of NMHC2A in the IP pTyr fraction (Fig $1 \mathrm{H}-\mathrm{M}$ ). In contrast, NMHC2A pTyr was impaired upon Dasatinib treatment (Dasa; Fig 1H, I), downregulation of Src kinase expression (shSrc; Fig 1J, K) or ectopic overexpression of a Src kinase dead mutant (KD; Fig 1L, M). Inversely, the ectopic overexpression of a constitutively active (CA) Src mutant increased NMHC2A pTyr upon LLO intoxication, to levels higher than those detected in cells expressing wild-type (WT) Src (Fig 1L, M). Notably, the low expression levels of Src CA and Src KD as compared to the wild-type version (Src WT) were sufficient to modulate the levels of NMHC2A pTyr (Fig 1L, M).

Altogether, these results show that LLO intoxication triggers Src activation and induces cortical localization of its active form, which is required for LLO-induced NMHC2A pTyr.

\section{Src kinase coordinates actomyosin cytoskeleton remodeling}

Next, we investigated whether the activation of Src kinase affects the assembly of LLO-induced NM2A cortical bundles, assembled during cell survival responses to PFT intoxication [21]. LLOtreated HeLa cells pre-incubated with Dasatinib or expressing low levels of Src were analyzed by immunofluorescence microscopy and compared to controls (Fig 2A). The percentage of cells displaying LLO-induced NM2A cortical structures was not affected by the impairment of SrC activity or expression (Fig 2B). However, in Src-deficient conditions, NM2A structures were smaller and seemed to be more enriched in NM2A when compared to controls (Fig 2A). In addition, while the majority of control cells displayed 1 or 2 NM2A structures, the percentage of cells displaying at least 3 bundles was significantly increased in cells lacking Src activity (Fig $2 \mathrm{C}, \mathrm{D})$. These data indicate that, while dispensable for the assembly of LLO-induced actomyosin cortical structures, Src activity is necessary to coordinate the remodeling of the cytoskeleton in response to intoxication. We hypothesized that Src activity might be critical for efficient cellular response to damage. We measured LLO-induced PM damage following propidium iodide (PI) incorporation by flow cytometry in NI or LLO-intoxicated HeLa cells, under control or Src-deficient conditions. As expected, the percentage of PI-positive cells significantly increased in LLO-intoxicated as compared to $\mathrm{NI}$ cells (Fig 2E). This increase was more pronounced in cells impaired in Src activity (Dasa) or with low Src expression (shSrc) (Fig 2E), indicating that active Src limits LLO-induced cellular damage. These results demonstrate that Src activity regulates the actomyosin cytoskeleton remodeling and contributes to PM repair upon LLO-intoxication.

We further analyzed the role of Src activity in the overall organization of the actomyosin cytoskeleton in non-intoxicated cells. Cells lacking Src activity or expression consistently showed more stress fibers as compared to control cells (Fig 2F). The overall percentage of cells displaying stress fibers significantly increased under impaired Src conditions (Fig 2G). To support these findings, we performed actin fractionation assays to measure the levels of 
globular and filamentous actin ( $\mathrm{g}$ - and f-actin). Src-impaired cells showed decreased levels of $\mathrm{g}$ actin (associated to the supernatant fraction, S) and concomitant increased levels of f-actin, which pellet upon ultracentrifugation $(\mathrm{P})(\mathrm{Fig} 2 \mathrm{H})$. In agreement with increased stress fibers detected by fluorescence microscopy, the g-/f-actin ratio was significantly reduced in Srcimpaired cells (Fig 2l). Together, these data indicate that besides being critical in the coordination of cytoskeletal responses to LLO-induced PM damage, Src activity controls the overall actomyosin cytoskeleton organization in HeLa cells in standard culture conditions.

\section{The status of NMHC2A pTyr interferes with the actomyosin cytoskeleton}

We previously reported that Listeria infection activates Src kinase [19], which in turn phosphorylates NMHC2A on the conserved tyrosine $158\left(\mathrm{Tyr}^{158}\right)$ [20]. We hypothesized that Src-mediated actomyosin remodeling observed during intoxication and in standard conditions, possibly occurs through NMHC2A pTyr ${ }^{158}$. To address that, we tested the impact of NMHC2A $\mathrm{pTyr}^{158}$ in the overall organization of the actomyosin cytoskeleton by fluorescence confocal microscopy. HeLa cells were transfected to express either a wild-type GFP-NMHC2A (WT), a mutant mimicking a permanent phosphorylation in which $\mathrm{Tyr}^{158}$ was replaced by a glutamate (Glu, GFP-NMHC2A-Y158E), or a non-phosphorylatable NMHC2A mutant in which Tyr ${ }^{158}$ was substituted by a phenylalanine (Phe, GFP-NMHC2A-Y158F). Compared to GFP-NMHC2A-WT, the expression of GFP-NMHC2A-Y158E led to strong NMHC2A aggregation in cells (Fig 3A, B, C). The aggregation phenotype, of which an acute example is depicted in Fig 3A, was reverted when GFP-NMHC2A-Y158E was co-expressed with the chaperone HSP90 (Fig S2), which facilitates NMHC2A folding and actomyosin filament assembly [11-13]. This suggests that aggregation might be related to GFP-NMHC2A-Y158E folding and/or assembly defects. Taking into account that GFP-NMHC2A-Y158E aggregation may trigger toxic effects in cells and that phosphomimetic mutations do not always mimic actual phosphorylations [29], we pursued our study with the non-phosphorylatable mutant (GFP-NMHC2A-Y158F).

The expression of GFP-NMHC2A-Y158F promoted the formation of stress fibers (Fig 3A, B, C), with similar orientation (anisotropic organization) to the one observed in GFP-NMHC2A-WT expressing cells (Fig S3). Actin fractionation assays on total lysates of transfected cells confirmed that indeed, the amount of $f$-actin associated to the pellet fraction was higher in GFPNMHC2A-Y158F than in GFP-NMHC2A-WT expressing cells (Fig 3D) and thus, the g-/f-actin ratio was significantly decreased (Fig $3 \mathrm{E}$ ). The percentage of transfected cells (Fig S4A) and the levels of expression of GFP-NMHC2A variants (Fig S4B) were verified by flow cytometry and were similar for the different constructs. Together these results reveal that stress fibers and polymerized actin accumulate in the absence of NMHC2A $\operatorname{Tyr}^{158}$ phosphorylation. Cells expressing the non-phosphorylatable NMHC2A-Y158F appear to stabilize the actin cytoskeleton and phenocopy results found in cells with reduced Src activity (Fig 2E-H). Thus, besides 
coordinating the actomyosin cytoskeleton by targeting ROCK and FAK [30], Src also regulates the cytoskeleton through the control of NMHC2A pTyr.

Given that stress fibers regulate the mechanical tension that contributes to the assembly of focal adhesions [31], we postulated that focal adhesions would also be affected by the NMHC2A pTyr status. Cells overexpressing the GFP-NMHC2A-WT or -Y158F were immunolabelled for vinculin, a marker for focal adhesions [32], and analyzed by confocal microscopy. Although the number of focal adhesions was decreased in GFP-NMHC2A-Y158F expressing cells (Fig 3F, G) these were larger and more elongated, displaying increased area and aspect ratio (Fig $3 \mathrm{~F}, \mathrm{H}, \mathrm{I})$. These data suggest that pTyr status of NMHC2A not only regulates stress fiber formation but also interferes with the assembly or disassembly of focal adhesions. These results show the importance of NMHC2A $\mathrm{pTyr}^{158}$ in the overall cytoskeletal organization and suggest its involvement in general processes such as cell adhesion and migration.

\section{NMHC2A pTyr interferes with cell size and controls cell motility}

To test if the status of NMHC2A pTyr ${ }^{158}$ indeed affects cell shape parameters and cell migration, we compared the area and aspect ratio of cells expressing GFP-NMHC2A-WT and Y158F. Expression of GFP-NMHC2A-Y158F led to slightly increased cell area (Fig 4A). Yet, aspect ratio values were similar in both conditions (Fig 4B).

To further evaluate the consequences of the cytoskeletal alterations induced by $\mathrm{NMHC} 2 \mathrm{~A}$ $\mathrm{pTyr}^{158}$, we monitored the motility of HeLa cells using fluorescent time-lapse microscopy (Movie M2). Tracking analysis of time-lapse videos revealed that cells expressing GFP-NMHC2AY158F migrated with reduced velocity (Fig 4C) and spanned shorter distances (Fig 4D), as compared to cells expressing GFP-NMHC2A-WT. These results are in line with elongated focal adhesions and increased stress fibers, which might indicate that cells are under more tension if the non-phosphorylatable NMHC2A is expressed. The NMHC2A pTyr ${ }^{158}$ status thus modulates cell motility, most likely through the control of the actomyosin cytoskeleton organization.

\section{NMHC2A pTyr does not affect mechanical and kinetic properties of NM2A in vitro}

$\mathrm{Tyr}^{158}$ is localized in the proximity of NM2A ATPase domain [20] (Fig S5A) and is conserved throughout evolution (Fig S5B). We thereby investigated if the observed actomyosin cytoskeleton alterations were related to perturbed NM2A ATPase activity or actin-binding by determining the mechanical and kinetic parameters of heavy meromyosin (HMM) fragments of human NMHC2A-WT as well as the variants Y158F and Y158E. The different HMM fragments were co-expressed and co-purified with the RLCs and ELCs from Sf9 insect cells (Fig S6A). Purified molecules were analyzed by electron microscopy and no apparent conformational changes were detected among the different HMM variants (NM2A-GFP-Flag ${ }^{\text {HMM }}$, Fig S6B), suggesting that the substitution of $\mathrm{Tyr}^{158}$ by a Phe or a Glu do not affect the overall HMM 
structure. The motor activity of the NM2A-GFP-Flag ${ }^{\mathrm{HMM}}$ variants was measured in a steady-state ATPase assay. Although the mutant molecules appeared to hydrolyze ATP at a slightly higher rate than the WT NM2A-GFP-Flag ${ }^{\mathrm{HMM}}$ (Fig 5A), this difference was not significative and the $\mathrm{K}_{m}$ and $\mathrm{V}_{\max }$ values obtained were similar (Fig $5 \mathrm{~B}$ ), and equivalent to those previously described [33]. This indicates that the pTyr status of the NMHC2A does not affect the ATPase activity of NM2A. The binding affinity of NM2A-GFP-Flag ${ }^{\text {HMM }}$ variants to actin was then assessed by cosedimentation assays in the absence or presence of ATP. As expected, actin alone pelleted by ultracentrifugation, whereas NM2A-GFP-Flag ${ }^{\mathrm{HMM}}$ variants remained in the supernatant in the absence of actin (Fig 5C). NM2A-GFP-Flag ${ }^{\mathrm{HMM}}$ molecules co-sedimented with actin in absence of the ATP but mainly remained in supernatants in the presence of $1 \mathrm{mM}$ of ATP (Fig 5C). The fraction of each NM2A-GFP-Flag ${ }^{\mathrm{HMM}}$ variant bound to actin in the presence of ATP was comparable for all conditions (Fig 5D). Corroborating this data, electron microscopy analysis of mixtures of actin and the different NM2A-GFP-Flag ${ }^{\text {HMM }}$ in presence or absence of ATP showed similar behaviors (Fig S6C). Finally, we assessed if NMHC2A Tyr $^{158}$ is involved in the velocity with which actin filaments slide on NM2A-GFP-Flag ${ }^{\mathrm{HMM}}$. We performed in vitro actin-gliding assays using coverslip-immobilized NM2A-GFP-Flag ${ }^{\text {HMM }}$. All the NM2A-GFP-Flag ${ }^{\text {HMM }}$ variants translocated actin at equivalent rates (Fig 5E and Movie M3) comparable to those previously reported for human NM2A [34].

These results demonstrate that the substitution of the $\operatorname{Tyr}^{158}$ by a Phe or Glu does not significantly affect the in vitro biochemical properties of NM2A.Thus, alterations detected on the cell cytoskeleton organization might be related to NM2A spatiotemporal mis-regulation rather than to altered NM2A enzymatic activity.

\section{NMHC2A pTyr regulates the assembly of NM2A bipolar filaments in cells}

We next examined whether $\mathrm{pTyr}^{158}$ could affect the assembly of NM2A bipolar filaments in the physiological intracellular environment. To investigate this, we performed Fluorescence Recovery After Photobleaching (FRAP) in HeLa cells overexpressing either the GFP-NMHC2AWT or -Y158F. The GFP signal of NM2A filaments from a single region per cell was photobleached and the dynamic recovery of the signal was followed overtime. Cells overexpressing GFP-NM2A-Y158F recovered GFP fluorescence faster than cells overexpressing the GFP-NMHC2A-WT (Fig 6A, B). In addition, while the GFP signal reached a plateau in GFP-NMHC2A-Y158F during the time of analysis, such signal continuously increased in GFP-NMHC2A-WT cells without reaching the plateau (Fig 6B). The mobile fraction, corresponding to the molecules able to turnover, and the half time required for the total recovery (T-half) were obtained from the fitting of recovery curves. Calculated mobile fractions were similar in both conditions (Fig 6C). However, the half-time of recovery was significantly shorter 
in cells expressing GFP-NMHC2A-Y158F as compared to cells expressing GFP-NMHC2A-Y158 WT (Fig 6D), indicating that non-phosphorylated NMHC2A allows faster NM2A turnover.

The phosphorylation of the RLC is essential for NM2A activation and promotes the assembly of actomyosin filaments [35]. Considering that GFP-NMHC2A-Y158F expressing cells display faster turnover of NM2A molecules on the bipolar filaments, we postulated that levels of phosphorylated RLC ( $p R L C$ ) are increased in these cells. We found that cells overexpressing the non-phosphorylatable NMHC2A (Y158F) displayed higher levels of pRLC than GFPNMHC2A-WT cells (Fig 6E, F). In addition, pRLC co-localized with stress fibers induced by the expression of GFP-NMHC2A-Y158F (Fig 6E). This data suggests that non-phosphorylated $\mathrm{Tyr}^{158}$ triggers NM2A activation and consequently promotes a faster turnover of the NM2A molecules on the bipolar filaments, which interferes with the actomyosin cytoskeletal dynamics.

\section{Deregulated NMY2 pTyr is pathogenic in vivo}

We finally evaluated the role of the NM2A pTyr ${ }^{158}$ in vivo, using as a model the $C$. elegans nonmuscle myosin 2 (NMY-2), homologous to the human NM2A protein (Fig S7). Point mutations were introduced by CRISPR/Cas9 in the nmy-2 genomic locus replacing the conserved tyrosine $163\left(\right.$ Tyr $^{163}$ ) by a non-phosphorylatable (Y163F) or phosphomimetic (Y163E) residue (Fig S7). To test the effects of each mutation in C. elegans, we analyzed the brood size (total number of the progeny laid) and the embryonic viability (percentage of viable embryos) of each strain. The homozygous strain expressing NMY-2 $2^{\mathrm{Y} 163 \mathrm{~F}}$ showed normal brood size and embryonic viability. In contrast, homozygous animals expressing NMY-2 ${ }^{\mathrm{Y} 163 \mathrm{E}}$ were sterile and therefore unable to lay embryos (Fig 7A), suggesting that $\operatorname{Tyr}^{163}$ phosphorylation status might have an impact on gonad function.

Given that $\mathrm{pTyr}^{158}$ of NMHC2A is driven by PFTs (Fig $1 \mathrm{~A}$ and B) and that PFT-intoxication affects $C$. elegans survival [36], we evaluated the susceptibility of wild-type and nmy-2(Y163F) animals to Cry5b, a PFT produced by Bacillus thuringiensis, which is a natural pathogen for nematodes [37]. As the nmy-2(Y163E) mutants lack progeny we did not analyze these. Adult wild-type and nmy-2(Y163F) animals were fed with control or Cry5b-expressing E. coli and the number of surviving animals was quantified every day, for 5 days. While, wild-type nonintoxicated worms survived and appeared healthy over time, those fed with Cry5b-expressing $E$. coli showed decreased survival (Fig 7B). Animals expressing NMY-2 ${ }^{\mathrm{Y} 163 \mathrm{~F}}$ showed slightly decreased survival when non-intoxicated but were significantly more susceptible to intoxication than those expressing wild-type NMY-2 (Fig 7B). These results suggest that a controlled regulation of NMY-2 phosphorylation at $\mathrm{Tyr}^{163}$ is necessary during the $C$. elegans response to Cry5b intoxication and possibly other stresses.

To evaluate this possibility, we assessed the role of the phosphorylation at $\mathrm{Tyr}^{163}$ in response to heat shock ( $1 \mathrm{~h}$ at $\left.35^{\circ} \mathrm{C}\right)$. Wild-type adults displayed higher survival when compared to $n m y$ - 
2(Y163F) animals (Fig 7C). Moreover, while the brood size upon heat shock was similar (Fig 7D), embryonic lethality was also higher in animals expressing the non-phosphorylatable NMY$2^{\mathrm{Y} 163 \mathrm{~F}}$ (Fig 7E). These data demonstrate that in $C$. elegans the regulation of NMY-2 Tyr ${ }^{163}$ phosphorylation is important for stress and survival responses to heat shock and PFT intoxication. 


\section{Discussion}

pTyr events are essential to respond to extracellular stimuli and regulate key cellular processes, including the reorganization of cytoskeleton [38,39]. We previously reported an uncharacterized pTyr event on NMHC2A, triggered by different bacterial infections [20]. In particular, infection by L. monocytogenes induced Src-dependent NMHC2A phosphorylation on $\mathrm{Tyr}^{158}$, which locates close to the ATP-binding pocket of NM2A and was predicted to be accessible for phosphorylation [40]. Here we showed that LLO, a L. monocytogenes secreted PFT and major virulence factor, is sufficient to trigger NMHC2A pTyr. We also found that, although NMHC2A $\mathrm{pTyr}^{158}$ does not interfere with the mechanical and motor properties of NM2A in vitro, the Srcdependent regulation of $\mathrm{pTyr}^{158}$ controls the organization and dynamics of actomyosin cytoskeleton. Ultimately, the phosphorylation status of NMHC2A Tyr $^{158}$ emerged as a key event for gonad function and for organism survival under stress conditions.

LLO has major roles in $L$. monocytogenes infection and triggers a plethora of signaling pathways via the activation of tyrosine kinases [41-43]. The mechanism underlying kinase activation remains unknown but possibly it is triggered by receptor clustering and activation at specific plasma membrane domains such as lipid rafts [43, 44]. Src activation was implicated on cytoskeletal stabilization and microtubule bundling in response to Pneumolysin, a PFT produced by Streptococcus pneumonia [45]. Moreover, other toxins target Src activity to alter the phosphorylation status of actin-binding proteins, thus promoting actin cytoskeleton rearrangements that support pathogen progression [46]. Our data demonstrates that during LLO intoxication, Src activity appears as a host protective response against PM damage. Src thus plays a broad role during infection, and its activation might benefit both the host and the pathogen.

Src is a cell volume regulator [47] found in blebs produced by hepatocellular swelling. Its activity controls membrane tension in NM2-dependent processes such as lamellipodial and axonal extension and regulates retraction of $\mathrm{PM}$ blebs upon osmotic and non-osmotic stress in a MLCK- or ROCK-dependent manner [48-52]. PFT-induced PM blebs are extruded or retracted in an NM2-dependent manner and they are associated with NM2A-enriched cortical structures [21-23]. We found active Src at sites of LLO-induced PM blebbing, suggesting that Src activation locally modulates the remodeling of the actomyosin cytoskeleton assisting the formation and retraction of PM blebs, which might sustain PM repair mechanisms.

Src is also a well-established oncogene. High Src activity reduces cell adhesion by triggering stress fiber disassembly [53-55], which enhances migration, invasion and tumor metastization $[56,57]$. In turn, low Src activity promotes stress fiber assembly associated to cell stiffening [56], and reduced cell migration by interfering with focal adhesions [58]. In line, Src-deficient fibroblasts show reinforced integrin and actomyosin cytoskeleton interactions [59], also limiting migration. Our data strikingly shows that cells overexpressing a non-phosphorylatable NM2A 
molecule on $\mathrm{Tyr}^{158}$ phenocopy the behavior of cells with impaired Src activity, which suggests that Src-dependent phosphorylation of NM2A $\mathrm{Tyr}^{158}$ might contribute to Src-mediated cell processes.

The assembly of stress fibers and focal adhesions depends on tension powered by NM2A contractility [60-63]. NM2A-Y158F-expressing cells display increased levels of phosphorylated myosin light chain and faster turnover of NM2A on bipolar filaments, which correlates with increased contractility. Bigger and elongated focal adhesions, together with increased number of fully organized stress fibers detected in NM2A-Y158F-expressing cells, suggest an altered contraction status, which correlates with increased tension, stronger adhesion and increased stiffness [56, 66, 67]. Indeed, traction-force microscopy analysis established a correlation between the size of focal adhesions and the force transmitted across them $[64,65]$. These data suggest that the phosphorylation status of $\mathrm{NMHC} 2 \mathrm{~A} \mathrm{Tyr}^{158}$ regulates the assembly/disassembly of focal adhesions and stress fibers thus proposing a novel mechanism to modulate cytoskeletal organization. In contrast, other studies propose that tension and myosin activity had little effect on both stress fibers and focal adhesions assembly [68-70]. Further studies are now necessary to dissect the molecular mechanisms through which NM2A pTyr ${ }^{158}$ is controlling the organization of the actomyosin cytoskeleton.

Given that the phosphorylation status of NMHC2A Tyr ${ }^{158}$ regulates the dynamics of the actomyosin bundles, it is possible that the phosphorylation on $\operatorname{Tyr}^{158}$ modulates the assembly and function of NM2 stacks, which are important for cytoskeleton remodeling and impact cell morphogenesis and migration [71]. The cellular mechanisms that drive morphogenesis depend on adhesion forces and on the activity of the actomyosin filaments [72], which are important in tissue wound healing and developmental closure events [73].

We attempted to use the variant NMHC2A Y158E as a phosphomimetic mutant. However, such mutants do not always mimic a permanent phosphorylation and thus data obtained and conclusions made are very limited. In HeLa cells NMHC2A Y158E was found to aggregate which suggest a toxic effect and/or decreased activation, as NM2A aggregation was reported for mutants affecting ATPase activity and ability to translocate actin filaments [74]. The aggregation of NMHC2A Y158E mutant was reverted by the overexpression of the cytosolic myosin chaperone HSP90, suggesting that NMHC2A Y158E molecules are still able to dissociate from aggregates, be activated and assemble into myosin filaments. Curiously, the HMM mutant did not appear to aggregate when expressed in Sf9 cells or after purification, when analyzed by electron microscopy. This may be due to the lack of a portion of the tail in this construct, which could possibly interact with the $\mathrm{pTyr}^{158}$, trigger aggregation, and thus inactivate the molecule when necessary. The expression of the phosphomimetic NMY2-Y163E in C. elegans renders the worms sterile indicating that this mutation does not sustain gonad function and once more suggesting a possible toxic effect of the mutation. 
The expression of motor-dead NMY2 mutants in C. elegans impairs the development of embryos [75]. However, the motor activity of the NM2A Y158E is not affected in vitro, suggesting that the phenotypes attributed to NMY2 Y163E are independent from myosin mechanical activity. Finally, taking into account that NMHC2A pTyr ${ }^{158}$ is triggered by infection and the phosphorylation status impacts stress response, it is tempting to hypothesize that the $\mathrm{pTyr}^{158}$ is critical for signaling and/or organizational responses to environmental assault and appears to be detrimental for organism development. Apart from $L m$ infection, the specific signals that trigger NMHC2A pTyr ${ }^{158}$ remain unidentified.

We propose a new mechanism for the regulation of the actomyosin cytoskeleton through the control of NM2A $\mathrm{pTyr}^{158}$. This actomyosin regulation adds a new layer of complexity in the control of the dynamics of cellular cytoskeleton with major impact on cell adhesion, migration and tissue organization. Our work also reveals new host factors protecting cells from bacterial infections contributing to the current knowledge regarding PM repair response against bacterial toxins. 


\section{Material and Methods}

Cell lines

HeLa cells (ATCC CCL-2) were grown in DMEM with glucose and L-glutamine (Lonza), supplemented with $10 \%$ fetal bovine serum (FBS; Biowest) and maintained at $37{ }^{\circ} \mathrm{C}$ in a $5 \%$ $\mathrm{CO}_{2}$ atmosphere.

\section{C. elegans strains}

C. elegans strains were maintained at $20^{\circ} \mathrm{C}$ on nematode growth medium (NGM) plates previously seeded with OP50 E. coli. Strains harboring NMY-2 point mutations (Y163F and Y163E) were generated by CRISPR/Cas9. Briefly, the gonads of young adult N2 worms were injected with three different sgRNA sequences expressed from pDD162 vector [76], which also contains the Cas- 9 gene re-encoded for $C$. elegans, and a single stranded repair template (ssODN) (IDT ultramer). A sgRNA and a single stranded repair template carrying the R92C mutation on the $d p y-10$ gene were co-injected, to allow identification of successfully injected worms through the described roller phenotype [77, 78]. sgRNAs and single stranded repair templates used are available in supplementary material. NMY-2 point mutations Y163F and Y163E were confirmed by genomic DNA sequencing. Outcrossing with N2 animals was performed for 6 generations to eliminate hypothetical off target mutations. Homozygous NMY-2Y163F was stored as GCP693.

\section{Reagents, toxins, antibodies and dyes}

Dasatinib (Santa Cruz Biotechnology) was used at $300 \mathrm{nM}$ in complete medium for 1 hour prior to LLO intoxication. LLO was expressed in E. coli BL21(DE3) and purified as described in [79]. Intoxications and washes were carried in Hanks' balanced salt solution (HBSS, Lonza). The following antibodies were used at 1/200 for immunofluorescence microscopy (IF) or 1/1,000 for immunoblotting (IB): rabbit anti-Src pTyr ${ }^{419}$ (\#44-660G, Invitrogen), mouse anti-active Src (\#AHO0051, Invitrogen), rabbit anti-Src (\#sc-18, Santa Cruz), mouse anti- $\beta$-actin (\#A1978, Sigma); mouse anti-phosphotyrosine (\#05-321, Millipore); rabbit anti-NMHC2A (\#M8064, Sigma); rabbit anti-calnexin (\#AB2301, Millipore), rabbit anti-vinculin (\#700062, Fisher Scientific), rabbit anti-pMLC (Thr18/Ser19) (\#3674, Cell Signaling), rabbit anti-NMY-2 (against residues 945-1368), mouse anti-a-tubulin (\#T5168, Sigma). For IF analysis, DNA was stained with 4',6-diamidino-2-phenylindole dihydrochloride (DAPI; Sigma) and actin with Rhodamine Phalloidin (Thermo Fisher Scientific) at 1/200; secondary antibodies were used at 1/500: goat anti-rabbit Alexa Fluor 488 (Invitrogen), goat anti-rabbit Alexa Fluor 594 (Invitrogen), goat anti-mouse Cy3 (Jackson ImmunoResearch). For IB, goat anti-rabbit or anti-mouse HRP (PARIS) were used at 1/10,000. 


\section{Plasmids}

Kras-Src FRET biosensor was a gift from Yingxiao Wang (Addgene plasmid \# 78302) [28]. Plasmids allowing the expression of wild-type Src kinase (WT), constitutively active Src (CA) and kinase dead Src (KD) were kindly provided by S. J. Parsons (University of Virginia) [80]. CMV-GFP-NMHCII-A plasmid was a gift from Robert Adelstein (Addgene plasmid \# 11347) [81]. pFastBac-NMHC2A ${ }^{\text {HMM }}$-GFP-Flag-WT, pFastBac-RLC and -ELC were described in [82]. Insertion of point mutations, Y158F and -Y158E, was achieved by site-directed mutagenesis using QuickChange II Site-directed mutagenesis kit (Agilent) as described [20].

\section{Transfections and shRNA lentiviral transductions}

HeLa cells seeded on top of glass coverslips in Nunc ${ }^{T M} 24$-well plates $\left(5 \times 10^{4}\right.$ cells/well), into Ibitreat $\mu$-dishes (Ibidi) $\left(1 \times 10^{5}\right.$ cells/well) or Nunc ${ }^{T M} 6$-well plates $\left(2.5 \times 10^{5}\right.$ cells/well) were respectively transfected with $0.5 \mu \mathrm{g}, 1 \mu \mathrm{\mu g}$ or $2,5 \mu \mathrm{g}$ of DNA using jetPRIME ${ }^{\circledR}$ Polyplus-transfection reagent or Lipofectamine $2000^{\circledR}$ (Thermo Fisher Scientific); according to the manufacturers' instructions. Protein expression was allowed for 18 to $24 \mathrm{~h}$ before cells were processed. shRNA lentiviral transductions were performed as described [20] and the sequences used are available in supplementary material.

\section{Immunoblot assays}

For HeLa cells, protein extracts were recovered in sample buffer $(0.25 \mathrm{mM}$ Tris- $\mathrm{Cl}$, pH 6.8; $10 \%$ SDS; $50 \%$ glycerol; and $5 \% \beta$-mercaptoethanol), resolved by SDS-PAGE ( $10 \%$ acrylamide) and transferred onto nitrocellulose membranes using a TransBlot Turbo ${ }^{\mathrm{TM}}$ system (BioRad), at $0.3 \mathrm{~A}$ for $1 \mathrm{~h}$. For $\mathrm{C}$. elegans, 60 adult worms/condition were harvested, washed 3 times in M9 containing $0.1 \%$ Triton X-100, centrifuged at $750 \mathrm{~g}$, resuspended in sample buffer supplemented with quartz sand (Sigma) corresponding to $1 / 3$ of the final volume. 3 cycles of 5 min boiling at $95^{\circ} \mathrm{C}$ followed by 5 min vortexing were performed. Samples were resolved by SDS-PAGE (7,5\% acrylamide) and transferred onto nitrocellulose membranes (Hybond ECL; GE Healthcare) at $0.22 \mathrm{~mA}$ for $2 \mathrm{~h}$ at $4^{\circ} \mathrm{C}$. Primary and secondary HRP-conjugated antibodies were diluted in TBS-Tween $0.1 \%(150 \mathrm{mM} \mathrm{NaCl} ; 50 \mathrm{mM}$ Tris- $\mathrm{HCl}, \mathrm{pH} 7.4$; and $0.1 \%$ Tween) with $5 \%(\mathrm{~m} / \mathrm{v})$ milk. Washes were performed with TBS-Tween $0.2 \%$. Signal was detected using Western Blotting Substrate (Thermo Fisher Scientific) and collected in a ChemiDoc ${ }^{\mathrm{TM}}$ XRS+ System with Image LabTM Software (BioRad).

\section{Immunofluorescence microscopy}

Cells were fixed in $3 \%$ paraformaldehyde (15 min), quenched with $20 \mathrm{mM} \mathrm{NH}_{4} \mathrm{Cl}(1 \mathrm{~h})$ and permeabilized with $0.1 \%$ Triton X-100 (5 min). Coverslips were incubated for $1 \mathrm{~h}$ with primary 
antibodies, washed three times in PBS $1 \mathrm{x}$ and incubated 45 min with secondary antibodies and when indicated, Rhodamine Phalloidin and DAPI. Antibodies and dyes were diluted in PBS containing 1\% BSA. Coverslips were mounted onto microscope slides with Aqua-Poly/Mount (Polysciences). Images were collected with a confocal laser-scanning microscope (Leica SP5 II) and processed using Fiji ${ }^{\mathrm{TM}}$ or Adobe Photoshop software.

\section{Fluorescence Resonance Energy Transfer (FRET)}

HeLa cells were seeded into Ibitreat $\mu$-dishes (Ibidi), transfected to express ECFP/YPet KrasSrc biosensor, maintained in HBSS or HBSS supplemented with LLO (2 nM) at $37^{\circ} \mathrm{C}$ in $5 \%$ $\mathrm{CO}_{2}$, and imaged using a confocal laser-scanning microscope (Leica SP8) equipped with a 40x 1.4 NA objective. Non-treated cells were imaged for $10 \mathrm{~min}$ prior LLO (2 nM) addition. Image acquisition of LLO-intoxicated cells started $20 \mathrm{~s}$ after LLO addition. ECFP/YPet fluorescence data sets with $0.42 \mu \mathrm{m}$ z-steps were acquired every $30 \mathrm{~s}$. Fiji ${ }^{\mathrm{TM}}$ was used for image sequence analysis and video assembly. For the quantification of the ECFP/YPet ratio, more than 30 cells were analyzed.

\section{Immunoprecipitation}

HeLa cells $\left(6 \times 10^{6}\right.$ cells $)$ treated as indicated were washed with PBS $1 \mathrm{x}$ and lysed in RIPA buffer (Santa Cruz). Lysates were recovered after centrifugation at $15,000 \mathrm{~g}\left(10 \mathrm{~min}\right.$ at $\left.4^{\circ} \mathrm{C}\right)$. Cell lysates (approximately $500 \mu \mathrm{g}$ ) were pre-cleared with protein A-immobilized PureProteome magnetic beads (Millipore) and incubated overnight $\left(4^{\circ} \mathrm{C}\right)$ with $1.5 \mu \mathrm{g}$ of anti-phosphotyrosine antibody (4G10 Millipore). Immune complexes were captured with $50 \mu$ of protein A-immobilized magnetic beads (Millipore) and processed for immunoblotting.

\section{Flow Cytometry}

For flow cytometry, $5 \times 10^{6}$ cells seeded in six-well plates $24 \mathrm{~h}$ before treatment, were intoxicated as indicated and washed twice in cold PBS 1x, trypsinized and resuspended in $0.5 \mathrm{ml}$ of cold PBS $1 x$ supplemented with $2 \%$ FBS. They were further incubated with $2 \mu \mathrm{g} / \mathrm{ml}$ of Propidium lodide (PI, Sigma) 5 min before flow cytometry analysis. At least 30000 events per sample were analyzed.

\section{g- and $f$-actin separation}

HeLa cells $\left(5 \times 10^{6}\right)$ were seeded in six-well plates and either transfected to express GFPNMHC2A-WT or -Y158F variants; or dasatinib-treated for $1 \mathrm{~h}$. Cells were washed twice with PBS $1 \mathrm{x}$ and homogenized $10 \mathrm{~min}$ at $37^{\circ} \mathrm{C}$ in actin stabilization buffer $(0.1 \mathrm{M}$ Hepes, $\mathrm{pH} 6.9$, $30 \%$ glycerol (v/v), 5\% DMSO (v/v), $1 \mathrm{mM} \mathrm{MgSO}_{4}, 1 \mathrm{mM}$ EGTA, 1\% Triton X-100 (v/v), $1 \mathrm{mM}$ 
ATP, complete protease and phosphatase inhibitors). Total protein fractions were ultracentrifuged at $100,000 \mathrm{~g}$ for $75 \mathrm{~min}$ at $37^{\circ} \mathrm{C}$. Supernatants containing g-actin were collected, and pellets containing f-actin resuspended in equivalent volume of RIPA buffer. Total, supernatant and pellet fractions were processed for immunoblotting.

Quantification of NMHC2A bundles or aggregates, stress fibers, focal adhesions and levels of phospho-regulatory light chain ( $p R L C)$

The percentage of cells with NM2A bundles and the number of NM2A bundles per cell were quantified in at least 200 cells per sample. Positive cells displayed at least a distinct cortical focus enriched in NM2A, each focus was quantified as a single NM2A bundle. The percentage of cells with stress fibers or NM2A aggregates was quantified in at least 200 cells per sample. Positive cells for stress fibers had approximately $50 \%$ (arbitrary) of the total cell area covered by dense actomyosin fibers and positive cells for aggregation displayed at least 2 distinct aggregates larger than $2 \mu \mathrm{m}$ or one larger than $5 \mu \mathrm{m}$. Anisotropy was quantified using the Fiji ${ }^{\mathrm{TM}}$ plug-in FibrilTool as described in [83] and focal adhesions were quantified as described in [84] using the CLAHE and Log3D FijiTM plug-ins. The levels of pRLC were quantified using Fiji ${ }^{\mathrm{TM}}$ by measuring in each cell the raw integrated density of pRLC normalized by the total cell area in at least 100 cells per sample.

\section{Cell motility analysis}

Cells were seeded into Ibitreat $\mu$-dishes (Ibidi), transfected to express the different GFPNMHC2A variants, maintained in OptiMEM (Gibco) at $37^{\circ} \mathrm{C}$ and $5 \% \mathrm{CO}_{2}$, and imaged using a widefield microscope (Leica DMI6000 Time-lapse) equipped with a 20x 0.4 NA objective. The data sets of transmitted light and the fluorescence of GFP-NMHC2A were acquired every 10 min during $16-20 \mathrm{~h}$. Fiji ${ }^{\mathrm{TM}}$ was used for image sequence analysis and video assembly. The velocity and accumulated distance were analyzed in at least 200 cells/condition using the Manual tracking plug-in from Fiji ${ }^{\mathrm{TM}}$.

NM2A-GFP-Flag ${ }^{H M M}-W T$, -Y158F and -Y158E expression in Sf9 cells

NM2A-GFP-Flag ${ }^{\mathrm{HMM}}$ variants were expressed in Sf9 insect cells, following the Bac-to-Bac $\circledast$ Baculovirus Expression System (Life Technologies) as recommended. Briefly, Sf9 cells were co-transfected with the pFastBac-NMHC2A ${ }^{\text {HMM }-G F P-F l a g-W T, ~ o r ~-Y 158 F, ~ o r ~-Y 158 E, ~ p F a s t B a c-~}$ RLC and -ELC bacmids, and incubated at $27^{\circ} \mathrm{C}$ for $96-120 \mathrm{~h}$. Supernatants were collected to harvest the viral stock $(P 1)$. Sf9 cells in suspension were then infected with $P 1(\mathrm{MOI}=1)$ to obtain a higher viral titer (P2) and incubated at $27^{\circ} \mathrm{C}$ with shaking. The process was repeated and the viral titer P3 was used to co-infect Sf9 cells for further expression and purification of the 
HMMs. Sf9 P3-infected cells were harvested after $72 \mathrm{~h}$ and used for purification or stored at $80^{\circ} \mathrm{C}$.

\section{NM2A-GFP-Flag ${ }^{H M M}$-WT, -Y158F and -Y158E purification}

Sf9 infected-cell pellets were resuspended in extraction buffer (15 mM MOPS pH 7.3, $200 \mathrm{mM}$

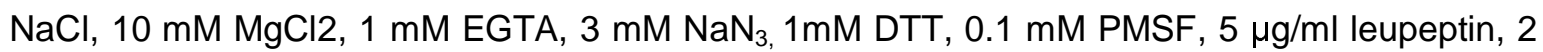
phosphatase inhibitors tablets) and lysed by sonication. The lysate was incubated with $1 \mathrm{mM}$ ATP for $15 \mathrm{~min}$, centrifuged at $19000 \mathrm{rpm}$ for $20 \mathrm{~min}$ and incubated with pre-washed anti-Flagresin (\#A2220, Sigma) for $3 \mathrm{~h}$ at $4^{\circ} \mathrm{C}$. Flag-resin was washed with high ionic strength buffer (10 mM MOPS pH 7.3, $0.1 \mathrm{mM}$ EGTA, $3 \mathrm{mM} \mathrm{NaN}_{3}, 0.5 \mathrm{M} \mathrm{NaCl}, 1 \mathrm{mM} \mathrm{ATP,} 5 \mathrm{mM} \mathrm{MgCl}$ and 0.1 $\mathrm{mM}$ PMSF), loaded into a column $\left(4^{\circ} \mathrm{C}\right)$ and further washed with 3 column volumes of low ionic strength buffer (10 mM MOPS pH 7.3, 0.1 mM EGTA, $3 \mathrm{mM} \mathrm{NaN}_{3}$ and $0.1 \mathrm{mM} \mathrm{PMSF}$ ). Proteins were eluted with 2 column volumes of Flag-peptide buffer $(0.5 \mathrm{mg} / \mathrm{ml}$ Flag peptide, $10 \mathrm{mM}$ MOPS pH 7.3, $0.1 \mathrm{mM}$ EGTA, $3 \mathrm{mM} \mathrm{NaN}_{3}, 100 \mathrm{mM} \mathrm{NaCl}$ and $0.1 \mathrm{mM}$ PMSF). Eluted fractions

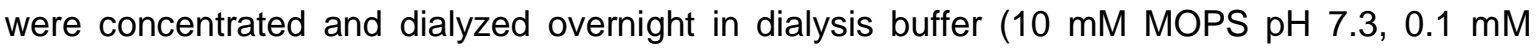
EGTA, $3 \mathrm{mM} \mathrm{NaN}_{3}, 0.5 \mathrm{M} \mathrm{NaCl}$ and $1 \mathrm{mM} \mathrm{DTT}$ ) at $4^{\circ} \mathrm{C}$. Aliquots of the purified proteins were quickly frozen in liquid nitrogen and stored at $-80^{\circ} \mathrm{C}$.

\section{Single molecule Electron Microscopy}

For NM2A-GFP-Flag ${ }^{\mathrm{HMM}}$ molecules in the absence of actin, samples were diluted to 50 nM HMM in $10 \mathrm{mM}$ MOPS pH 7.0, $50 \mathrm{mM} \mathrm{NaCl}, 2 \mathrm{mM} \mathrm{MgCl}, 0.1 \mathrm{mM}$ EGTA. NM2A-GFPFlag $^{\mathrm{HMM}}$ molecules were mixed with F-actin to give final concentrations of $100 \mathrm{nM}$ of $\mathrm{HMM}$ and $500 \mathrm{nM}$ of F-actin. Samples were handled as previously described [4]. Briefly, $5 \mu \mathrm{l}$ of the sample was applied to a carbon-coated copper grid (pre-exposed to UV light to produce a hydrophilic surface) and stained with $1 \%$ uranyl acetate. Data were recorded at room temperature on a JEOL 1200EX II microscope equipped with an AMT XR-60 CCD camera. The FijiTM FFT bandpass filter (40 - 2 pixels, auto-scaled) was applied to images prior to making figures, in order to enhance the clarity of individual molecules.

\section{ATPase activity assay}

Actin-activated Mg-ATPase activities were determined by previously described NADH-linked assay [7, 85]. Purified NM2A-GFP-Flag ${ }^{\mathrm{HMM}}$ variants were phosphorylated for at least $30 \mathrm{~min}$ at room temperature, in adequate buffer conditions $(0.2 \mathrm{mM}$ ATP, $0.2 \mathrm{mM} \mathrm{CaCl}, 10 \mu \mathrm{g} / \mathrm{ml} \mathrm{MLCK}$ and $1 \mu \mathrm{M}$ CaM). Mg-ATPase activities were determined in $10 \mathrm{mM}$ MOPS, $0.1 \mathrm{mM}$ EGTA, 50 $\mathrm{mM} \mathrm{NaCl}, 2 \mathrm{mM} \mathrm{MgCl} 2,3.4 \mathrm{mM} \mathrm{ATP}$, growing actin concentrations $(0-120 \mu \mathrm{M}), 40$ units $/ \mathrm{ml}$ lactate dehydrogenase, 200 units $/ \mathrm{ml}$ pyruvate kinase, $1 \mathrm{mM}$ phosphoenolpyruvate, $0.2 \mathrm{mM}$ $\mathrm{NADH}$ and non-phosphorylated or phosphorylated HMMs $(0.1-0.2 \mu \mathrm{M})$. The conversion of 
$\mathrm{NADH}$ into $\mathrm{NAD}^{+}$was determined by measuring the $\mathrm{A}_{340}\left(\square=6220 \mathrm{M}^{-1} \mathrm{~cm}^{-1}\right)$ every second for 20 min. Data were corrected for the background Mg-ATPase activity of actin alone. The MgATPase activity of the different NM2A-GFP-Flag ${ }^{\mathrm{HMM}}$ variants at $0 \mu \mathrm{M}$ actin concentration was further subtracted to each data point. To determine the kinetic constants $V_{\max }$ and $K_{m}$, the experimental data sets were fitted to the Michaelis-Menten mathematical equation using Prism 8.

\section{Co-sedimentation assay}

$2 \mu \mathrm{M}$ of each NM2A-GFP-Flag ${ }^{\mathrm{HMM}}$ variant was incubated for 30 min at room temperature with 10 $\mu \mathrm{M}$ filamentous actin in the absence or presence of $1 \mathrm{mM} \mathrm{ATP}$, in a buffer containing $10 \mathrm{mM}$ MOPS, $0.1 \mathrm{mM}$ EGTA, $100 \mathrm{mM} \mathrm{NaCl}, 2 \mathrm{mM} \mathrm{MgCl}_{2}, 3 \mathrm{mM} \mathrm{NaN}_{3}$, and $1 \mathrm{mM}$ DTT. Samples containing only the NM2A-GFP-Flag ${ }^{\mathrm{HMM}}$ variants or filamentous actin were used as sedimentation controls. Samples were centrifuged at $100,000 x g$ for $30 \mathrm{~min}$ at $4^{\circ} \mathrm{C}$. Supernatant and pellet fractions were recovered and loading buffer was added equivalently. Each sample $(20 \mu \mathrm{l})$ was analyzed on a 4-12\% Bis-Tris gel (Life Technologies), stained with Coomassie Blue and scanned on an Odyssey system (Li-Cor Biosciences).

In vitro motility assay

In vitro motility assays were performed as described [86]. Briefly, $60 \mu \mathrm{l}$ of NM2A-GFP-Flag ${ }^{\mathrm{HMM}}$ molecules $(0.2 \mathrm{mg} / \mathrm{ml})$ in motility buffer (MB: $20 \mathrm{mM}$ MOPS, pH 7.3, $0.1 \mathrm{mM}$ EGTA, $2 \mathrm{mM}$ $\mathrm{MgCl}_{2}$ ) with $0.5 \mathrm{M} \mathrm{NaCl}$ were trapped in a flow cell. NM2A-GFP-Flag ${ }^{\mathrm{HMM}}$ molecules attached to the coverslip were further incubated with $50 \mu \mathrm{MB}$ with $0.5 \mathrm{M} \mathrm{NaCl}$ and $1 \mathrm{mg} / \mathrm{ml} \mathrm{BSA}$, washed in $\mathrm{MB}$ with $50 \mathrm{mM} \mathrm{NaCl}$ (LS buffer) and incubated for 4 min with $35 \mu \mathrm{l}$ of $1 \mathrm{mM} \mathrm{ATP}, 0.2 \mathrm{mM}$ $\mathrm{CaCl}_{2}, 1 \mathrm{mM}$ ATP, $1 \mu \mathrm{M}$ CaM, $1 \mathrm{nM}$ MLCK and $10 \mu \mathrm{M}$ of unlabeled actin in LS buffer. Coverslips were washed in LS buffer and incubated with $30 \mu \mathrm{l}$ of labelled actin filaments (20 nM Rhodamine phalloidin actin in $50 \mathrm{mM}$ DTT) for $35 \mathrm{~s}$. The excess solution was removed and the flow cell was loaded for $1 \mathrm{~min}$ with $40 \mu \mathrm{l}$ of MB with $0.7 \%$ of methylcellulose, $1 \mathrm{mM}$ ATP, $50 \mathrm{mM}$ $\mathrm{KCl}, 50 \mathrm{mM}$ DTT, $2.5 \mathrm{mg} / \mathrm{ml}$ glucose, $2.5 \mu \mathrm{g} / \mathrm{ml}$ glucose oxidase, and $45 \mu \mathrm{g} / \mathrm{ml}$ catalase. The slides were imaged at $25^{\circ} \mathrm{C}$, at 5 second intervals for 2 minutes, on an inverted Nikon Eclipse Ti-E microscope with an H-TIRF module attachment, a CFI60 Apochromat TIRF 100X Oil Immersion Objective Lens (N.A. 1.49, W.D. $0.12 \mathrm{~mm}$, F.O.V $22 \mathrm{~mm}$ ) and an EMMCD camera (Andor iXon Ultra 888 EMCCD, $1024 \times 1024$ array, $13 \mu \mathrm{m}$ pixel). Velocity of the actin filaments on top of the different NM2A-GFP-Flag ${ }^{\mathrm{HMM}}$ molecules was quantified using the FAST algorithm described in [87].

Fluorescence Recovery After Photobleaching (FRAP) 
HeLa cells were transfected to express either GFP-NMHC2A-WT or -Y158F. Images were acquired $20 \mathrm{~h}$ after transfection using a laser scan confocal microscope SP8 (Leica) equipped with a $63 \times 1.3 \mathrm{NA}$ objective, at $37^{\circ} \mathrm{C}$ and $5 \% \mathrm{CO}_{2}$. Five pre-bleach images were acquired each $138 \mathrm{~ms}$, followed by five bleaching scans with $100 \%$ intensity on the 488-nm laser line over the region of interest (ROI). Recovery of fluorescence was monitored for 56 s every $138 \mathrm{~ms}$ (400 frames), followed by 60 s every 300 ms (200 frames). Mean fluorescence intensities (MFI) were measured on Fiji ${ }^{\mathrm{TM}}$ and fluorescence recovery analysis was performed as described in [88], using easyFRAP-web on-line platform (https://easyfrap.vmnet.upatras.gr/). Briefly, the MFI of the bleached $\mathrm{ROI}$ is normalized to a non-bleached ROI, and corrected for the differences in starting intensities and the loss in total fluorescence. Additionally, the MFI is corrected for differences of the bleaching efficiencies. The mobile fraction and the half-maximal recovery time (t-half) values were obtained by curve fitting. Only cells for which fitted curves showed $a R^{2} \geq$ 0.8 were considered to quantify the mobile fraction and t-half.

\section{Brood size and lethality in C. elegans}

Synchronized L1 worms of N2 and GCP693 strains were grown in NGM plates at $20^{\circ} \mathrm{C}$ for $72 \mathrm{~h}$. Animals were singled out to fresh NGM plates, allowed to lay eggs for $72 \mathrm{~h}$ and removed from the plate. Embryos were allowed to hatch for additional $24 \mathrm{~h}$ before brood size and lethality quantification. Embryonic viability was calculated from the percentage of hatched eggs divided by the total number of progenies.

\section{Cry5b intoxication assay}

Synchronized L1 worms of N2 and GCP693 strains, were grown in NGM plates at $20^{\circ} \mathrm{C}$ for $50 \mathrm{~h}$ and transferred, each 2 days for a period of 5 days, to NGM plates previously seeded with control (empty vector) or Cry5B-expressing E. coli [89]. Briefly, saturated cultures of $E$. coli transformed with the $\mathrm{pQE}$ empty vector or $\mathrm{PQE}-\mathrm{Cry5B}$ vector were diluted (10x) in LB with 100 $\mu \mathrm{g} / \mathrm{ml}$ ampicillin at grown for $1 \mathrm{~h}$ at $37^{\circ} \mathrm{C}$ with shaking. Expression of Cry5B was induced with 1 $\mathrm{mM}$ IPTG for $3 \mathrm{~h}$ at $30^{\circ} \mathrm{C} .100 \mu \mathrm{l}$ of each culture at $\mathrm{OD}=2+/-0.1$ were plated onto NGM plates containing $2 \mathrm{mM} \mathrm{IPTG}$ and $100 \mu \mathrm{g} / \mathrm{ml}$ ampicillin, and incubated at $25^{\circ} \mathrm{C}$ overnight. Animals not responding to touch were considered dead.

\section{Heat Shock assay}

Synchronized L1 worms of N2 and GCP693 strains, were grown as described above for $50 \mathrm{~h}$. L4 animals in specific NGM plates for each strain were left at $20^{\circ} \mathrm{C}$ or incubated in a $35^{\circ} \mathrm{C}$ bath for $1 \mathrm{~h}$. Animals were incubated for additional $24 \mathrm{~h}$ at $20^{\circ} \mathrm{C}$, singled out onto fresh NMG plates and allowed to lay eggs for $24 \mathrm{~h}$ at $20^{\circ} \mathrm{C}$. Brood size and lethality were assessed $48 \mathrm{~h}$ later. 


\section{Statistical analysis}

Statistical analyses were carried out with Prism 8 (version 8.1.1), GraphPad Software, La Jolla California USA, www.graphpad.com), using one-way ANOVA with Dunnett's post hoc analysis to compare different means in relation to a control sample and Tukey's post hoc analysis for pairwise comparisons of more than two different means. Two-way ANOVA with Šídák's post hoc analysis was used to compare each sample mean with other sample mean, in the same condition. Two-tailed unpaired and paired Student's $t$-test was used for comparison of means between two samples. 


\section{References}

1. Sellers, J.R. and S.M. Heissler, Nonmuscle myosin-2 isoforms. Curr Biol, 2019. 29(8): p. R275-R278.

2. Heissler, S.M. and D.J. Manstein, Nonmuscle myosin-2: mix and match. Cell Mol Life Sci, 2013. 70(1): p. 1-21.

3. Brito, C. and S. Sousa, Non-Muscle Myosin 2A (NM2A): Structure, Regulation and Function. Cells, 2020. 9(7).

4. Billington, N., et al., Characterization of three full-length human nonmuscle myosin II paralogs. J Biol Chem, 2013. 288(46): p. 33398-410.

5. Heissler, S.M. and J.R. Sellers, Various Themes of Myosin Regulation. J Mol Biol, 2016. 428(9 Pt B): p. 1927-46.

6. Vicente-Manzanares, M., et al., Non-muscle myosin II takes centre stage in cell adhesion and migration. Nat Rev Mol Cell Biol, 2009. 10(11): p. 778-90.

7. De La Cruz, E.M. and E.M. Ostap, Kinetic and equilibrium analysis of the myosin ATPase. Methods Enzymol, 2009. 455: p. 157-92.

8. Aguilar-Cuenca, R., et al., Tyrosine Phosphorylation of the Myosin Regulatory Light Chain Controls Non-muscle Myosin II Assembly and Function in Migrating Cells. Curr Biol, 2020. 30(13): p. 2446-2458 e6.

9. Dulyaninova, N.G. and A.R. Bresnick, The heavy chain has its day: regulation of myosin-II assembly. Bioarchitecture, 2013. 3(4): p. 77-85.

10. Breckenridge, M.T., N.G. Dulyaninova, and T.T. Egelhoff, Multiple regulatory steps control mammalian nonmuscle myosin II assembly in live cells. Mol Biol Cell, 2009. 20(1): p. 338-47.

11. Lehtimaki, J.I., et al., UNC-45a promotes myosin folding and stress fiber assembly. J Cell Biol, 2017. 216(12): p. 4053-4072.

12. Srikakulam, R., L. Liu, and D.A. Winkelmann, Unc45b forms a cytosolic complex with Hsp90 and targets the unfolded myosin motor domain. PLoS One, 2008. 3(5): p. e2137.

13. Liu, L., R. Srikakulam, and D.A. Winkelmann, Unc45 activates Hsp90-dependent folding of the myosin motor domain. J Biol Chem, 2008. 283(19): p. 13185-93.

14. Lecuit, T. and P.F. Lenne, Cell surface mechanics and the control of cell shape, tissue patterns and morphogenesis. Nat Rev Mol Cell Biol, 2007. 8(8): p. 633-44.

15. Pecci, A., et al., MYH9: Structure, functions and role of non-muscle myosin IIA in human disease. Gene, 2018. 664: p. 152-167.

16. Newell-Litwa, K.A., R. Horwitz, and M.L. Lamers, Non-muscle myosin II in disease: mechanisms and therapeutic opportunities. Dis Model Mech, 2015. 8(12): p. 1495-515.

17. Ma, X. and R.S. Adelstein, The role of vertebrate nonmuscle Myosin II in development and human disease. Bioarchitecture, 2014. 4(3): p. 88-102.

18. Tan, L., et al., Non-muscle Myosin II: Role in Microbial Infection and Its Potential as a Therapeutic Target. Front Microbiol, 2019. 10: p. 401.

19. Sousa, S., et al., Src, cortactin and Arp2/3 complex are required for E-cadherin-mediated internalization of Listeria into cells. Cell Microbiol, 2007. 9(11): p. 2629-43.

20. Almeida, M.T., et al., Src-dependent tyrosine phosphorylation of non-muscle myosin heavy chain-IIA restricts Listeria monocytogenes cellular infection. J Biol Chem, 2015. 290(13): p. 8383-95.

21. Mesquita, F.S., et al., Endoplasmic reticulum chaperone Gp96 controls actomyosin dynamics and protects against pore-forming toxins. EMBO Rep, 2017. 18(2): p. 303-318.

22. Mesquita, F.S., et al., Control of cytoskeletal dynamics during cellular responses to pore forming toxins. Commun Integr Biol, 2017. 10(5-6): p. e1349582. 
23. Brito, C., et al., Perfringolysin O-Induced Plasma Membrane Pores Trigger Actomyosin Remodeling and Endoplasmic Reticulum Redistribution. Toxins (Basel), 2019. 11(7).

24. Brito, C., et al., Mechanisms protecting host cells against bacterial pore-forming toxins. Cell Mol Life Sci, 2019. 76(7): p. 1319-1339.

25. Encarnacao, M., et al., A Rab3a-dependent complex essential for lysosome positioning and plasma membrane repair. J Cell Biol, 2016. 213(6): p. 631-40.

26. Roskoski, R., Jr., Src protein-tyrosine kinase structure and regulation. Biochem Biophys Res Commun, 2004. 324(4): p. 1155-64.

27. Harrison, S.C., Variation on an Src-like theme. Cell, 2003. 112(6): p. 737-40.

28. Ouyang, M., et al., Determination of hierarchical relationship of Src and Rac at subcellular locations with FRET biosensors. Proc Natl Acad Sci U S A, 2008. 105(38): p. 14353-8.

29. Heissler, S.M. and J.R. Sellers, Four things to know about myosin light chains as reporters for non-muscle myosin-2 dynamics in live cells. Cytoskeleton (Hoboken), 2015. 72(2): p. 65-70.

30. Lee, H.H., et al., Src-dependent phosphorylation of ROCK participates in regulation of focal adhesion dynamics. J Cell Sci, 2010. 123(Pt 19): p. 3368-77.

31. Burridge, K. and C. Guilluy, Focal adhesions, stress fibers and mechanical tension. Exp Cell Res, 2016. 343(1): p. 14-20.

32. Humphries, J.D., et al., Vinculin controls focal adhesion formation by direct interactions with talin and actin. J Cell Biol, 2007. 179(5): p. 1043-57.

33. Kovacs, M., et al., Mechanism of blebbistatin inhibition of myosin II. J Biol Chem, 2004. 279(34): p. 35557-63.

34. Cuda, G., et al., In vitro actin filament sliding velocities produced by mixtures of different types of myosin. Biophys J, 1997. 72(4): p. 1767-79.

35. Vicente-Manzanares, M. and A.R. Horwitz, Myosin light chain mono- and diphosphorylation differentially regulate adhesion and polarity in migrating cells. Biochem Biophys Res Commun, 2010. 402(3): p. 537-42.

36. Huffman, D.L., et al., Pore worms: using Caenorhabditis elegans to study how bacterial toxins interact with their target host. Int J Med Microbiol, 2004. 293(7-8): p. 599-607.

37. Leyns, F., et al., Nematicidal activity of Bacillus thuringiensis isolates. Fundamental and Applied Nematology, 1995. 18(3): p. 211-218.

38. Xie, Y., et al., Quantitative profiling of spreading-coupled protein tyrosine phosphorylation in migratory cells. Sci Rep, 2016. 6: p. 31811.

39. Hunter, T., Tyrosine phosphorylation: thirty years and counting. Curr Opin Cell Biol, 2009. 21(2): p. 140-6.

40. Harney, D.F., R.K. Butler, and R.J. Edwards, Tyrosine phosphorylation of myosin heavy chain during skeletal muscle differentiation: an integrated bioinformatics approach. Theor Biol Med Model, 2005. 2: p. 12.

41. Gekara, N.O., et al., The multiple mechanisms of $\mathrm{Ca} 2+$ signalling by listeriolysin $\mathrm{O}$, the cholesterol-dependent cytolysin of Listeria monocytogenes. Cell Microbiol, 2007. 9(8): p. 2008-21.

42. Gekara, N.O. and S. Weiss, Lipid rafts clustering and signalling by listeriolysin $O$. Biochem Soc Trans, 2004. 32(Pt 5): p. 712-4.

43. Gekara, N.O., et al., The cholesterol-dependent cytolysin listeriolysin $O$ aggregates rafts via oligomerization. Cell Microbiol, 2005. 7(9): p. 1345-56.

44. Zaas, D.W., et al., The role of lipid rafts in the pathogenesis of bacterial infections. Biochim Biophys Acta, 2005. 1746(3): p. 305-13.

45. Iliev, A.I., et al., Rapid microtubule bundling and stabilization by the Streptococcus pneumoniae neurotoxin pneumolysin in a cholesterol-dependent, non-lytic and Src-kinase 
dependent manner inhibits intracellular trafficking. Mol Microbiol, 2009. 71(2): p. 46177.

46. Tegtmeyer, N. and S. Backert, Role of Abl and Src family kinases in actin-cytoskeletal rearrangements induced by the Helicobacter pylori CagA protein. Eur J Cell Biol, 2011. 90(11): p. 880-90.

47. Cohen, D.M., SRC family kinases in cell volume regulation. Am J Physiol Cell Physiol, 2005. 288(3): p. C483-93.

48. Tournaviti, S., et al., SH4-domain-induced plasma membrane dynamization promotes bleb-associated cell motility. J Cell Sci, 2007. 120(Pt 21): p. 3820-9.

49. Barfod, E.T., et al., Src regulates distinct pathways for cell volume control through Vav and phospholipase Cgamma. J Biol Chem, 2005. 280(27): p. 25548-57.

50. Barfod, E.T., et al., Myosin light chain kinase and Src control membrane dynamics in volume recovery from cell swelling. Mol Biol Cell, 2011. 22(5): p. 634-50.

51. Suter, D.M. and P. Forscher, Transmission of growth cone traction force through apCAM-cytoskeletal linkages is regulated by Src family tyrosine kinase activity. J Cell Biol, 2001. 155(3): p. 427-38.

52. Raucher, D. and M.P. Sheetz, Cell spreading and lamellipodial extension rate is regulated by membrane tension. J Cell Biol, 2000. 148(1): p. 127-36.

53. Tarone, G., et al., Rous sarcoma virus-transformed fibroblasts adhere primarily at discrete protrusions of the ventral membrane called podosomes. Exp Cell Res, 1985. 159(1): p. 141-57.

54. Fincham, V.J., A. Chudleigh, and M.C. Frame, Regulation of p190 Rho-GAP by v-Src is linked to cytoskeletal disruption during transformation. J Cell Sci, 1999. 112 ( Pt 6): p. 947-56.

55. Pawlak, G. and D.M. Helfman, MEK mediates $v$-Src-induced disruption of the actin cytoskeleton via inactivation of the Rho-ROCK-LIM kinase pathway. J Biol Chem, 2002. 277(30): p. 26927-33.

56. Tavares, S., et al., Actin stress fiber organization promotes cell stiffening and proliferation of pre-invasive breast cancer cells. Nat Commun, 2017. 8: p. 15237.

57. Frame, M.C., Newest findings on the oldest oncogene; how activated src does it. J Cell Sci, 2004. 117(Pt 7): p. 989-98.

58. Frame, M.C., et al., v-Src's hold over actin and cell adhesions. Nat Rev Mol Cell Biol, 2002. 3(4): p. 233-45.

59. Felsenfeld, D.P., et al., Selective regulation of integrin--cytoskeleton interactions by the tyrosine kinase Src. Nat Cell Biol, 1999. 1(4): p. 200-6.

60. Vicente-Manzanares, M., et al., Regulation of protrusion, adhesion dynamics, and polarity by myosins IIA and IIB in migrating cells. J Cell Biol, 2007. 176(5): p. 573-80.

61. Pasapera, A.M., et al., Myosin II activity regulates vinculin recruitment to focal adhesions through FAK-mediated paxillin phosphorylation. J Cell Biol, 2010. 188(6): p. 877-90.

62. Even-Ram, S., et al., Myosin IIA regulates cell motility and actomyosin-microtubule crosstalk. Nat Cell Biol, 2007. 9(3): p. 299-309.

63. Chrzanowska-Wodnicka, M. and K. Burridge, Rho-stimulated contractility drives the formation of stress fibers and focal adhesions. J Cell Biol, 1996. 133(6): p. 1403-15.

64. Balaban, N.Q., et al., Force and focal adhesion assembly: a close relationship studied using elastic micropatterned substrates. Nat Cell Biol, 2001. 3(5): p. 466-72.

65. Schwarz, U.S., et al., Calculation of forces at focal adhesions from elastic substrate data: the effect of localized force and the need for regularization. Biophys J, 2002. 83(3): p. 1380-94. 
66. Luo, Q., et al., Cell stiffness determined by atomic force microscopy and its correlation with cell motility. Biochim Biophys Acta, 2016. 1860(9): p. 1953-60.

67. Efremov, Y.M., et al., Anisotropy vs isotropy in living cell indentation with AFM. Sci Rep, 2019. 9(1): p. 5757.

68. Hotulainen, P. and P. Lappalainen, Stress fibers are generated by two distinct actin assembly mechanisms in motile cells. J Cell Biol, 2006. 173(3): p. 383-94.

69. Stricker, J., et al., Myosin II-mediated focal adhesion maturation is tension insensitive. PLoS One, 2013. 8(7): p. e70652.

70. Thievessen, I., et al., Vinculin-actin interaction couples actin retrograde flow to focal adhesions, but is dispensable for focal adhesion growth. J Cell Biol, 2013. 202(1): p. 163-77.

71. Jiu, Y., et al., Myosin-18B Promotes the Assembly of Myosin II Stacks for Maturation of Contractile Actomyosin Bundles. Curr Biol, 2019. 29(1): p. 81-92 e5.

72. Koenderink, G.H., et al., An active biopolymer network controlled by molecular motors. Proc Natl Acad Sci U S A, 2009. 106(36): p. 15192-7.

73. Munjal, A. and T. Lecuit, Actomyosin networks and tissue morphogenesis. Development, 2014. 141(9): p. 1789-93.

74. Hu, A., F. Wang, and J.R. Sellers, Mutations in human nonmuscle myosin IIA found in patients with May-Hegglin anomaly and Fechtner syndrome result in impaired enzymatic function. J Biol Chem, 2002. 277(48): p. 46512-7.

75. Osorio, D.S., et al., Crosslinking activity of non-muscle myosin II is not sufficient for embryonic cytokinesis in C. elegans. Development, 2019. 146(21).

76. Dickinson, D.J., et al., Engineering the Caenorhabditis elegans genome using Cas9triggered homologous recombination. Nat Methods, 2013. 10(10): p. 1028-34.

77. Levy, A.D., J. Yang, and J.M. Kramer, Molecular and genetic analyses of the Caenorhabditis elegans dpy-2 and dpy-10 collagen genes: a variety of molecular alterations affect organismal morphology. Mol Biol Cell, 1993. 4(8): p. 803-17.

78. Arribere, J.A., et al., Efficient marker-free recovery of custom genetic modifications with CRISPR/Cas9 in Caenorhabditis elegans. Genetics, 2014. 198(3): p. 837-46.

79. Glomski, I.J., et al., The Listeria monocytogenes hemolysin has an acidic pH optimum to compartmentalize activity and prevent damage to infected host cells. J Cell Biol, 2002. 156(6): p. 1029-38.

80. Wilson, L.K., et al., pp60c-src tyrosine kinase, myristylation, and modulatory domains are required for enhanced mitogenic responsiveness to epidermal growth factor seen in cells overexpressing c-src. Mol Cell Biol, 1989. 9(4): p. 1536-44.

81. Wei, Q. and R.S. Adelstein, Conditional expression of a truncated fragment of nonmuscle myosin II-A alters cell shape but not cytokinesis in HeLa cells. Mol Biol Cell, 2000. 11(10): p. 3617-27.

82. Wang, F., et al., A conserved negatively charged amino acid modulates function in human nonmuscle myosin IIA. Biochemistry, 2000. 39(18): p. 5555-60.

83. Boudaoud, A., et al., FibrilTool, an ImageJ plug-in to quantify fibrillar structures in raw microscopy images. Nat Protoc, 2014. 9(2): p. 457-63.

84. Horzum, U., B. Ozdil, and D. Pesen-Okvur, Step-by-step quantitative analysis of focal adhesions. MethodsX, 2014. 1: p. 56-9.

85. Wang, F., et al., Kinetic mechanism of non-muscle myosin IIB: functional adaptations for tension generation and maintenance. J Biol Chem, 2003. 278(30): p. 27439-48.

86. Sellers, J.R., In vitro motility assay to study translocation of actin by myosin. Curr Protoc Cell Biol, 2001. Chapter 13: p. Unit 132.

87. Aksel, T., et al., Ensemble force changes that result from human cardiac myosin mutations and a small-molecule effector. Cell Rep, 2015. 11(6): p. 910-920. 
88. Koulouras, G., et al., EasyFRAP-web: a web-based tool for the analysis of fluorescence recovery after photobleaching data. Nucleic Acids Res, 2018. 46(W1): p. W467-W472.

89. Bischof, L.J., D.L. Huffman, and R.V. Aroian, Assays for toxicity studies in C. elegans with Bt crystal proteins. Methods Mol Biol, 2006. 351: p. 139-54. 


\section{Figure legends}

Figure 1. LLO promotes NMHC2A pTyr through Src activation in HeLa cells. (A, B) NMHC2A levels measured by immunoblots on whole-cell lysates (WCL) and IP fractions of pTyr proteins (IP pTyr) from non-intoxicated (NI) or LLO-intoxicated (LLO; $0.5 \mathrm{nM}, 15 \mathrm{~min}$ ) HeLa cells. Actin was used as loading control. (B) NMHC2A levels in IP pTyr fraction were quantified and normalized to those detected in the WCL. Each dot corresponds to an independent experiment. Data correspond to mean \pm SEM $(n=5)$; $p$-value was calculated using two-tailed unpaired Student's $t$-test, ${ }^{* *} p<0.01$. (C, D) Levels of $\mathrm{Tyr}^{419}$-phosphorylated Src (Src pTyr ${ }^{419}$ ) and total Src detected by immunoblots on whole-cell lysates of HeLa cells non-intoxicated (NI) or intoxicated with $0.5 \mathrm{nM}$ LLO for 5 and $15 \mathrm{~min}$. Actin was used as loading control. (D) Levels of Src pTyr ${ }^{419}$ were quantified and normalized to the levels of total Src. Each dot corresponds to an independent experiment. Values are the mean $\pm \operatorname{SEM}(n=6) ; p$-values were calculated using one-way ANOVA with Tukey's post hoc analysis, ${ }^{* *} p<0.01$ and ${ }^{* * *} p<0.001$. (E) Sequential frames of time-lapse confocal microscopy FRET analysis of $\mathrm{NI}$ or LLO-intoxicated HeLa cells expressing ECFP/YPet-based Src biosensor. LLO was added to the culture medium $20 \mathrm{~s}$ before acquisition. Arrows indicate LLO-induced plasma membrane (PM) blebbing sites. Scale bar,10 $\mu \mathrm{m}$. (F) Kinetics of donor/acceptor fluorescence emission ratio (ECFP/YPet) of the Src biosensor in $\mathrm{NI}$ and LLO-intoxicated cells. Values correspond to the mean $\pm \operatorname{SEM}(n>30)$; $p$-values were calculated using one-way ANOVA with Dunnett's post hoc analysis, ${ }^{* * *} p<0,001$. (G) Confocal microscopy images of $\mathrm{NI}$ or LLO-intoxicated (0.5 nM, $15 \mathrm{~min}$ ) HeLa cells, immunolabelled for active Src (red) and NMHC2A (green) and stained with DAPI (blue). Insets show LLO-induced cortical NMHC2A structures enriched in active Src. Scale bar, $10 \mu \mathrm{m}$. (H, J, L) Immunoblots of NMHC2A, total Src and Src pTyr ${ }^{419}$ levels on WCL or IP pTyr fractions of non-intoxicated (-) or LLO-intoxicated $(0.5 \mathrm{nM}, 15 \mathrm{~min})(+)$ HeLa cells $\mathbf{( H )}$ in absence (mock) or presence of Dasatinib (300 nM, 1h) (Dasa); (J) expressing control (shCtr) or Src specific oligos (shSrc) and (L) ectopically expressing wild-type Src (WT), constitutively active Src (CA) or kinase dead Src (KD) variants. Actin was used as loading control. (I, K, M) Quantification of the levels of NMHC2A in IP fractions normalized to those detected in WCL, under the different conditions. Each dot corresponds to an independent experiment. Values correspond to the mean \pm SEM $(n \geq 3)$ and $p$-values were calculated using $(\mathbf{I}, \mathbf{M})$ one-way ANOVA with Dunnett's post hoc analysis, ${ }^{*} p<0.05,{ }^{* *} p<0.01$ or $(\mathbf{K})$ two-tailed unpaired Student's $t$-test, ${ }^{* * *} p<0.001$.

Figure 2. Src kinase orchestrates the response to LLO-intoxication by controlling actomyosin cytoskeleton dynamics in HeLa cells. (A) Confocal microscopy images of LLOintoxicated (0.5 nM, $15 \mathrm{~min}$ ) HeLa cells in control (mock and shCtr) and Src-impaired (Dasatinib-treated and shSrc) conditions. Cells were immunolabelled for NMHC2A (greyscale) 
and stained with DAPI (blue). Scale bar, $10 \mu \mathrm{m}$. (B) Percentage of cells displaying NMHC2A structures in mock, Dasatinib-treated (Dasa), shCtr and shSrc HeLa cells, intoxicated as in (A). Values are the mean $\pm \operatorname{SEM}(n=3)$. (C ,D) Percentage of LLO-intoxicated cells showing 1-2, 35 or $>5$ NMHC2A structures, under the conditions as in $(A)$. Values are the mean $\pm \operatorname{SEM}(n=3)$; $p$-values were calculated using two-way ANOVA with Sidak's post hoc analysis, ${ }^{*} p<0.05,{ }^{* *} p$ $<0.01,{ }^{* * *} p<0.001$. (C) shows data from cells under Src chemical inhibition (Dasatinib). (D) shows data from cells in which Src expression was downregulated through shRNAs. (E) Percentage of PI-positive HeLa cells in non-intoxicated (NI) conditions or LLO-intoxicated as in (A), measured by flow cytometry analysis. Values are the mean $\pm \operatorname{SEM}(n=4)$; $p$-values were calculated using one-way ANOVA with Dunnett's post hoc analysis, ${ }^{*} p<0.05$. (F) Confocal microscopy images of control (mock and shCtr) and Src-impaired (Dasatinib-treated and shSrc) HeLa cells stained with phalloidin for actin (greyscale) and with DAPI (blue). Scale bar, $10 \mu \mathrm{m}$. (G) Percentage of cells with stress fibers quantified from images similar to those in $(F)$. Values are the mean $\pm \operatorname{SEM}(n=4)$; $p$-values were calculated using two-tailed unpaired Student's $t$-test, ${ }^{*} p<0.05,{ }^{* *} p<0.01$. (H) Immunoblots showing the levels of globular (g)- and filamentous (f)actin in HeLa cells treated as in (F). g- and f-actin from the total cell lysates (T) were separated by ultracentrifugation. g-actin was recovered from supernatant fractions (S) while f-actin was associated with pellet fractions $(\mathrm{P})$. Calnexin was used as loading control ( $\mathrm{Cnx}$ ). Actin levels are shown with both short exposure (SE) and long exposure (LE). (I) Quantification of $\mathrm{g} / \mathrm{f}$-actin ratio obtained from immunoblot signals. Values are the mean $\pm \operatorname{SEM}(n=4) ; p$-values were calculated using two-tailed unpaired Student's $t$-test, ${ }^{*} p<0.05,{ }^{* * *} p<0.001$. In (B, C, D, E, G and I) each dot or triangle corresponds to an independent experiment.

Figure 3. NMHC2A pTyr regulates stress fiber and focal adhesion formation in HeLa cells. (A) Representative confocal microscopy images of HeLa cells ectopically expressing either GFP-NMHC2A-WT, -Y158E or -Y158F (green) and stained with phalloidin for actin (red) and DAPI (blue). Scale bar, $10 \mu \mathrm{m}$. (B, C) Scoring of the percentage of cells displaying (B) NMHC2A aggregation or (C) stress fibers in HeLa cells ectopically expressing the different NMHC2A variants. Each dot corresponds to an independent experiment. Values are the mean \pm SEM $(n \geq$ 6); $p$-values were calculated using one-way ANOVA with Tukey's post hoc analysis, ${ }^{*} p<0.05$. (D) Immunoblots showing the levels of globular ( $g$ )- and filamentous ( $f$ )-actin in HeLa cells ectopically expressing NMHC2A WT or Y158F variants. $g$ - and f-actin from the total cell lysates (T) were separated by ultracentrifugation. $g$-actin was recovered from supernatant fractions (S) while f-actin was associated with pellet fractions $(P)$. Calnexin was used as loading control (Cnx). (E) Immunoblots quantification of the $\mathrm{g} / \mathrm{f}$-actin ratio. Each dot corresponds to an independent experiment. Values are the mean \pm SEM $(n=3)$; $p$-values were calculated using one-way ANOVA with Tukey's post hoc analysis, ${ }^{* *} p<0.01$. (F) Representative confocal 
microscopy images of HeLa cells ectopically expressing GFP-NMHC2A-WT or -Y158F (green), immunolabelled for vinculin (red) and stained with DAPI (blue). Insets show differential focal adhesions morphology. Scale bar, $10 \mu \mathrm{m}$. (G) Quantification of the number of focal adhesions per cell, from images similar to $F$. Each dot corresponds to the mean number of focal adhesions per cell obtained from 3 independent experiments. Values are the mean \pm SEM; $p$-values were calculated using one-way ANOVA with Tukey's post hoc analysis, ${ }^{* * *} p<0.001$. $(\mathbf{H}, \mathbf{I})$ Quantification of the $(\mathbf{H})$ focal adhesion area and $(\mathbf{I})$ aspect ratio in HeLa cells as in F. Each dot corresponds to a single focal adhesion. Values are the mean \pm SEM $(n>140)$; $p$-values were calculated using one-way ANOVA with Tukey's post hoc analysis, ${ }^{* * *} p<0.001$.

Figure 4. NMHC2A pTyr status alters cell size and motility. (A, B) Quantification of cell shape parameters of HeLa cells ectopically expressing the GFP-NMHC2A-WT or Y158F: (A) area and $(\mathbf{B})$ aspect ratio. Cells were stained with phalloidin for actin and quantifications were performed using Fiji ${ }^{\mathrm{TM}}$. Each dot represents a single cell. Values are the mean \pm SEM $(n>160)$; $p$-value was calculated using one-way ANOVA with Tukey's post hoc analysis, ${ }^{* *} p<0.01$. (C, D) Quantification of cell motility parameters using the Manual Tracking plugin of Fiji ${ }^{T M}$ (C) velocity and (D) accumulated distance in HeLa cells as in A. The data was obtained from movies similar to Movie M2. Each dot represents a single cell. Values are the mean \pm SEM $(n>200) ; p$-values were calculated using one-way ANOVA with Tukey's post hoc analysis, ${ }^{*} \mathrm{p}<0.05,{ }^{* * *} \mathrm{p}<0.001$.

Figure 5. NMHC2A pTyr does not affect myosin 2A (NM2A) mechanical or kinetic properties. (A) Actin-activated Mg-ATPase activity of heavy meromyosin (HMM) NM2A-GFPFlag $^{\text {HMM }}-\mathrm{WT},-\mathrm{Y} 158 \mathrm{~F}$ and $-\mathrm{Y} 158 \mathrm{E}$ determined by the conversion of NADH into NAD ${ }^{+}$. Three independent preparations of each NM2A-GFP-Flag ${ }^{\text {HMM }}$ variant were used in at least 3 independent experiments. Data sets were fitted to a hyperbolic equation to determine the kinetic constants, $K_{m}$ and $V_{\max }$ (B) Plot of the $K_{m}$ and $V_{\max }$ values. Data represent the mean $\pm S E M$ from at least 6 independent experiments (per actin concentration) and using the 3 different preparations of NM2A-GFP-Flag ${ }^{H M M}$ variants. Each dot represents the value obtained for a single preparation. Values are the mean \pm SEM $(n=3)$. (C) Representative actin cosedimentation assay of NM2A-GFP-Flag ${ }^{\text {HMM }}$ WT, -Y158F and -Y158E. Supernatants (S) and pellets $(P)$ obtained from ultracentrifugation of mixtures of either NM2A-GFP-Flag ${ }^{\mathrm{HMM}}-\mathrm{WT}$, Y158F or -Y158E with or without $10 \mu \mathrm{M}$ actin and 1mM ATP, are shown by coomassie blue staining. Actin alone is also shown. Regulatory light chain (RLC); Essential light chain (ELC). (D) Quantification of co-sedimentation assays showing myosin fraction bound to actin (pellet) in presence of ATP. Each dot corresponds to a single preparation of each NM2A-GFP-Flag ${ }^{H M M}$ variant. Values are the mean $\pm \operatorname{SEM}(n=3)$. (E) Gaussian distribution of the velocity of actin filaments moving on top of either NM2A-GFP-Flag ${ }^{\text {HMM }}-$ WT, -Y158F or -Y158E. Values were 
obtained from at least 5 independent motility assays (Movie M3) performed on 3 independent NM2A-GFP-Flag ${ }^{\text {HMM }}$ preparations. 500 to 1300 filaments were quantified for each condition and per independent experiment.

Figure 6. NMHC2A pTyr ${ }^{158}$ controls the dynamic assembly of bipolar filaments in HeLa cells. (A) Representative confocal microscopy time-lapse images of Fluorescence Recovery After Photobleaching (FRAP) experiments, in HeLa cells ectopically overexpressing either the GFP-NMHC2A-WT or -Y158F. Insets of the bleached region in dashed lines. Scale bar, $5 \mu \mathrm{m}$ (B) Plot of the normalized mean fluorescence intensity recovery curves obtained for each condition tested (black, WT; green, Y158F). Values are the mean \pm SEM ( $n \geq 40$ cells). (C, D) Quantification of the (C) mobile fraction and the (D) half-maximal recovery time (t-half) obtained from the curve fitting of each individual recovery curve. Each dot represents a single cell. Values are the mean \pm SEM ( $n \geq 40$ cells); $p$-values were calculated using one-way ANOVA with Tukey's post hoc analysis, * $p<0.05$. (E) Representative confocal microscopy images of HeLa cells ectopically expressing either the GFP-NMHC2A-WT or -Y158F (green), immunolabelled to detect pMLC (red) and stained with DAPI (blue). Scale bar, $15 \mu \mathrm{m}$. (F) Levels of pMLC in cells expressing the different NMHC2A variants, quantified with Fiji ${ }^{\mathrm{TM}}$. Each dot corresponds to a single cell. Values are the mean \pm SEM $(n>300)$; $p$-values were calculated using one-way ANOVA with Tukey's post hoc analysis, ${ }^{* * *} p<0.001$.

Figure 7. Fine-tuned regulation of NMY2 pTyr is necessary for $C$. elegans gonad function, survival to intoxication and stress response. (A) Brood size and embryonic viability of $C$. elegans expressing NMY-2 WT, NMY-2 ${ }^{\mathrm{Y} 163 \mathrm{~F}}$ or NMY-2 ${ }^{\mathrm{Y} 163 \mathrm{E}}$. Each dot represents the brood size of a single worm. Values are the mean $\pm \operatorname{SEM}(n \geq 10)$. (B) Survival of the different $C$. elegans strains fed for 5 days with control E. coli (NI WT; NI Y163F) or with E. coli expressing the Cry5B toxin (Cry5B WT; Cry5B Y163F). Each curve represents the mean of 3 independent experiments with 30 worms per condition. Values are the mean $\pm \operatorname{SEM}(n=3)$; $p$-values were calculated using two-way ANOVA with Sidak's post hoc analysis, ${ }^{* *} p<0.001$. (C) Percentage of survival of NMY-2 WT and NMY-2 ${ }^{\mathrm{Y} 163 \mathrm{~F}} \mathrm{C}$. elegans strains $24 \mathrm{~h}$-post a $1 \mathrm{~h}$-heat shock at $35^{\circ} \mathrm{C}$. Each dot represents an independent experiment with 8-10 worms per condition. Values are the mean \pm SEM $(n=4)$; $p$-values were calculated using two-tailed paired Student's $t$-test, ${ }^{*} p<$ 0.05. (D) Brood size of $C$. elegans that survived to the $1 \mathrm{~h}$-heat shock at $35^{\circ} \mathrm{C}$. Each dot represents the brood size of a single worm. Values are the mean \pm SEM $(n \geq 10)$; $p$-values were calculated using two-tailed paired Student's $t$-test, ${ }^{*} p<0.05$, ${ }^{* *} p<0.01$. (E) Embryonic viability after 1 h-heat shock. Each dot represents the \% of viability of embryos from a single worm. Values are the mean \pm SEM $(n \geq 8)$; $p$-values were calculated using two-tailed paired Student's $t$-test, ${ }^{*} p<0.05,{ }^{* * *} p<0.001$. 


\section{Supplementary figures}

Figure S1. Src kinase is activated upon LLO-intoxication of HeLa cells. (A) Levels of active Src (non-phosphorylated at $\mathrm{Ty}^{530}$ ) assessed by immunoblot on total lysates of HeLa cells nonintoxicated ( $\mathrm{NI}$ ) or intoxicated for 5 and $15 \mathrm{~min}$ with $0.5 \mathrm{nM}$ LLO. Actin detection served as loading control. (B) Levels of active Src quantified and normalized to the actin levels. Each dot corresponds to a single independent experiment. Values are the mean \pm SEM $(n=6) ; p$-values were calculated using two-tailed unpaired Student's $t$-test, ${ }^{*} p<0.05$.

Figure S2. HSP90 overexpression in GFP-NMHC2A-WT, -Y158F and -Y158E expressing cells. $\mathrm{NMHC} 2 \mathrm{~A}$ aggregation in HeLa cells ectopically expressing the different NMHC2A variants with or without co-expression of HSP90. Control conditions (Ctr) relate to the results shown in Fig $3 C$. Values are the mean \pm SEM $(n \geq 3)$; $p$-values were calculated using one-way ANOVA with Tukey's post hoc analysis, ${ }^{*} p<0.05$.

Figure S3. Quantification of the anisotropic distribution of stress fibers in HeLa cells ectopically expressing GFP-NMHC2A-WT or Y158F. Each dot corresponds to a single cell. Values are the mean \pm SEM $(n>200)$;

Figure S4. Transfection and expression levels of the different NMHC2A variants in HeLa cells. (A) Percentage of transfected cells determined by the quantification of GFP positive cells by flow cytometry. Each dot corresponds to a single independent experiment. Values are the mean $\pm \operatorname{SEM}(n=3)(B)$ Expression levels of the different constructs shown as MFI (mean fluorescence intensity) of the GFP positive cells, determined by flow cytometry. Each dot corresponds to a single independent experiment. Values are the mean \pm SEM $(n=3)$; $p$-values were calculated using one-way ANOVA with Tukey's post hoc analysis, ${ }^{*} p<0.05$.

Figure S5. NMHC2A Tyr ${ }^{158}$ localization and conservation throughout evolution. (A) Ribbon representation of the head domain of $\mathrm{NMHC} 2 \mathrm{~A}$ (green) to show $\operatorname{Tyr}^{158}$ (purple) and ADP (magenta) localization. The ELC (light yellow) and the actin-binding pocket (violet) are shown. PDB entry 1BR4. (B) NMHC2A amino-acid sequence analysis from different species and focused on the region involving the $\mathrm{Tyr}^{158}$, adapted from [20].

Figure S6. Purified NM2A-GFP-Flag ${ }^{\text {HMM }}$ molecules from baculovirus-infected Sf9 cells. (A) SDS-polyacrylamide gel stained with Coomassie Blue showing the separation of the purified heavy mero-myosins (HMM), and the regulatory and essential light chains (RLC and ELC, 
respectively) for each NM2A-GFP-Flag ${ }^{\mathrm{HMM}}$ variant. (B) Representative single molecule electron microscopy images showing either a NM2A-GFP-Flag ${ }^{\text {HMM }}$-WT, Y158F or Y158E molecule. Scale bar, $10 \mathrm{~nm}$. (C) Electron microscopy images showing the bound and unbound status of all purified NM2A-GFP-Flag ${ }^{\text {HMM }}$ variants to actin filaments in the absence or presence of ATP. Scale bar, $100 \mathrm{~nm}$.

Figure S7. Comparison of myosin protein sequence in different species. Protein sequence analysis of the non-muscle myosin $2 A$ from $H$. sapiens, $M$. musculus and $C$. elegans, focused in the region containing the $\mathrm{Tyr}^{158}$ in NM2A. The position of the corresponding residue in the other organisms is indicated. 


\section{Supplementary Material}

Table 1. C. elegans strains used in this study.

\begin{tabular}{|c|l|c|}
\hline Strain & \multicolumn{1}{|c|}{ Genotype } & Source \\
\hline N2 & Ancestral strain & \\
\hline GCP693 & nmy-2 [prt144(Y163F)]I & $\begin{array}{c}\text { This } \\
\text { study }\end{array}$ \\
\hline
\end{tabular}

Table 2. shRNA sequences for Src knockdown in HeLa cells and single-guide RNAs, singlestranded repair templates and RNAi sequences used in C. elegans.

\begin{tabular}{|c|c|c|}
\hline \multicolumn{2}{|c|}{ shRNA Sequences (5'-3') } & Source \\
\hline shControl-SHC016 & $\begin{array}{l}\text { CCGGGCGCGATAGCGCTAATAAT } \\
\text { TTCTCGAGAAATTATTAGCGCTAT } \\
\text { CGCGCTTTTT }\end{array}$ & \multirow{2}{*}{ Sigma } \\
\hline shSrc-TRCN0000023597 & $\begin{array}{l}\text { CCGGGTGGCTTACTACTCCAAAC } \\
\text { ATCTCGAGATGTTTGGAGTAGTA } \\
\text { AGCCACTTTTT }\end{array}$ & \\
\hline \multicolumn{2}{|c|}{ sgRNAs sequences (5'-3') } & \\
\hline NMY-2_Y163_Guide\#1_top & cttGTCTTGAAGCATGCTGCGGT & \multirow{3}{*}{ Sigma } \\
\hline NMY-2_Y163_Guide\#2_top & cttGTCGTTCTTGAAGCATGCTG & \\
\hline NMY-2_Y163_Guide\#3_top & cttGATGCTGCGGTAGGCTTCAT & \\
\hline \multicolumn{2}{|c|}{ Single stranded repair templates ( $\left.5^{\prime}-3^{\prime}\right)$} & \\
\hline ssODN NMY2_Y163F & $\begin{array}{l}\text { AGA AAG GAG ATG CCA CCA } \\
\text { CAC ATA TTT GCT GTT GCT GAT } \\
\text { GAA GCT TTC CGC TCA ATG CTC } \\
\text { CAG GAA CGA GAT GAT CAG TCA } \\
\text { ATT CTC TGC ACG TTA GT }\end{array}$ & \multirow[b]{2}{*}{ IDT ultramer } \\
\hline ssODN NMY2_Y163E & $\begin{array}{l}\text { AGA AAG GAG ATG CCA CCA } \\
\text { CAC ATA TTT GCT GTT GCT GAT } \\
\text { GAA GCT GAG CGC TCA ATG } \\
\text { CTC CAG GAA CGA GAT GAT } \\
\text { CAG TCA ATT CTC TGC ACG TTA } \\
\text { GT }\end{array}$ & \\
\hline
\end{tabular}


Movie 1. Src is activated in response to LLO intoxication in HeLa cells. HeLa cells expressing ECFP/YPet-based Src biosensor were imaged by time-lapse microscopy during 10 min (Non-intoxicated). LLO was added to a final concentration of $2 \mathrm{nM}$ and cells were further imaged for $30 \mathrm{~min}$. Sequential frames acquired every $30 \mathrm{~s}$ (15 frames per second display rate) show the ECFP (cyan) and YPet (yellow) fluorescence intensity separately, and the ECFP/YPet ratio (color bar). Scale bar, $10 \mu \mathrm{m}$.

Movie 2. Ectopic expression of the different GFP-NMHC2A variants affects cell motility in HeLa cells. HeLa cells ectopically expressing GFP-NMHC2A-WT or -Y158F were followed by time-lapse microscopy for more than $15 \mathrm{~h}$. (Upper panel) Sequential frames acquired every 10 min (8 frames per second display rate). Overlay of the transmitted light and the fluorescence of GFP-NMHC2A variants is shown. Scale bar, $50 \mu \mathrm{m}$. (Lower panel) Representative tracking of the movement of cells expressing the different versions of NMHC2A, produced by the Manual Tracking plug-in on Fiji ${ }^{\mathrm{TM}}$. Scale bar, $50 \mu \mathrm{m}$.

Movie 3. NMHC2A pTyr does not affect the associated actin motility assay. Rhodaminephalloidin-labeled actin filaments moving on top of either the NM2A-GFP-Flag ${ }^{\text {HMM }}-\mathrm{WT},-\mathrm{Y} 158 \mathrm{~F}$ or -Y158E. Sequential frames were acquired every $1 \mathrm{~s}$ for 2 min (15 frames per second display rate). Scale bar - $20 \mu \mathrm{m}$. 
bioRxiv preprint doi: https://doi.org/10.1101/2020.08.12.246090; this version posted August 13, 2020. The copyright holder for this preprint (which was not certified by peer review) is the author/funder. All rights reserved. No reuse allowed without permission. 


\section{A}

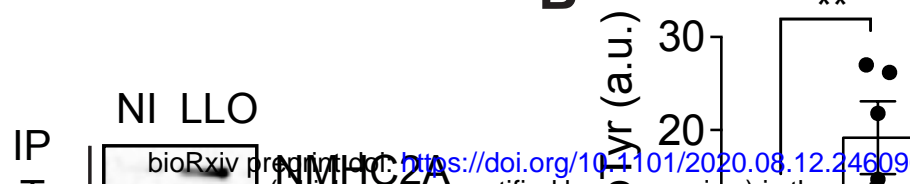
pTyr (wich wastot certified by per revigw) is the autholffunder. A WCL $\begin{aligned} & m \text { NMHC2A } \\ & -\infty \text { Actin }\end{aligned}$

C

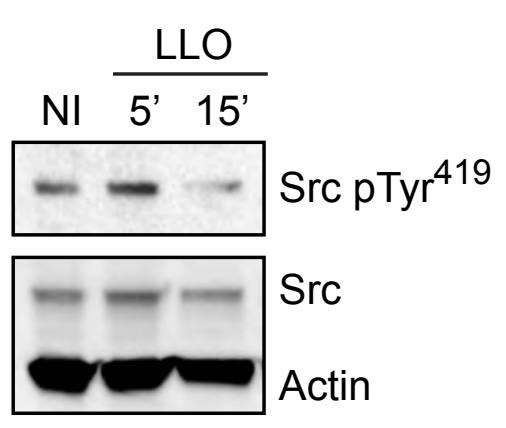

E
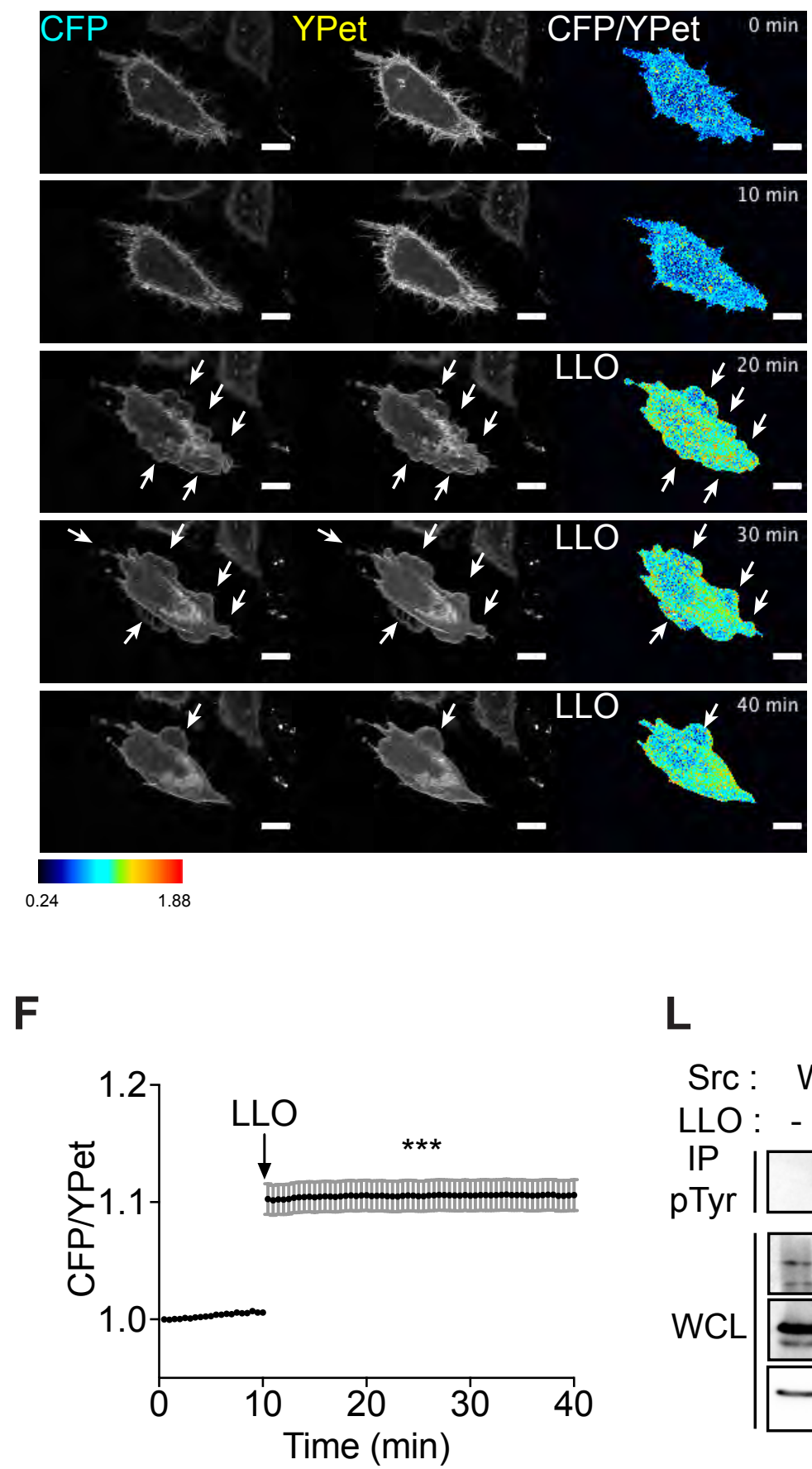

\section{H}

Mock Dasa
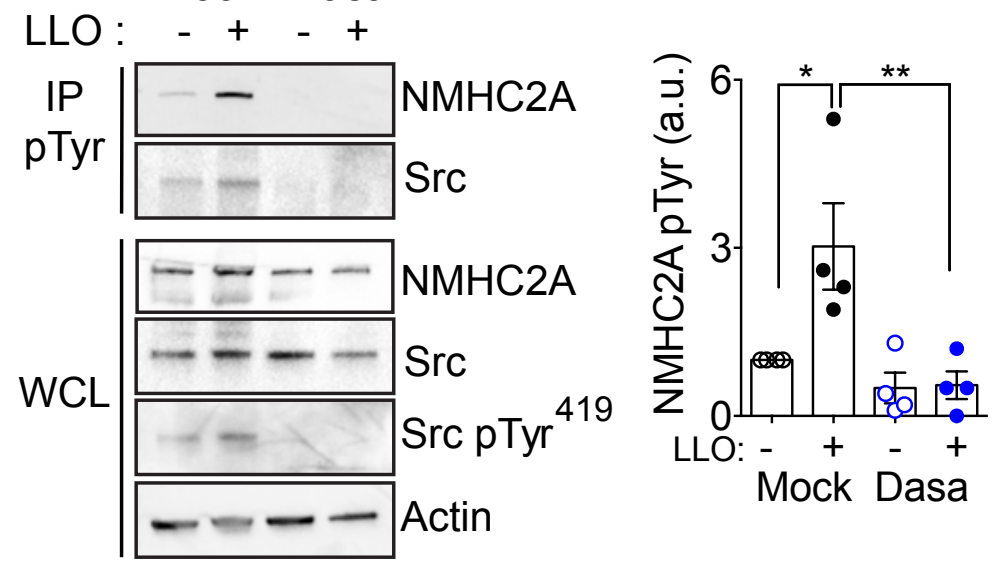

J

K

shCtr shSrc
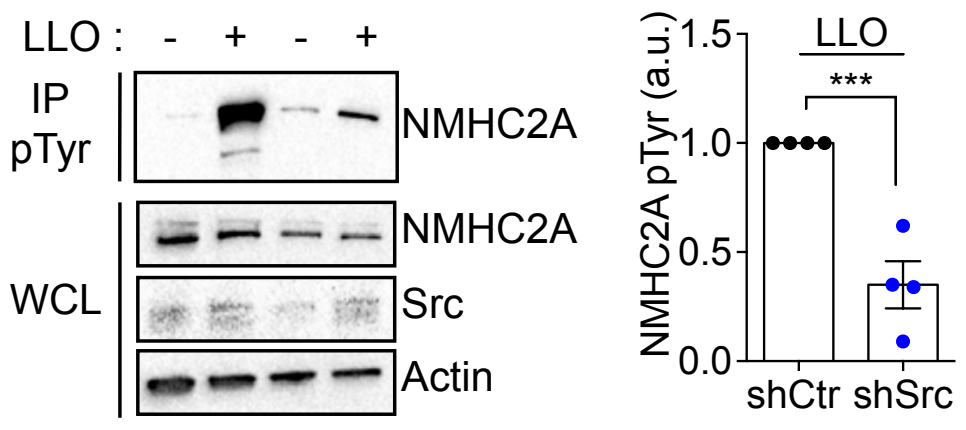

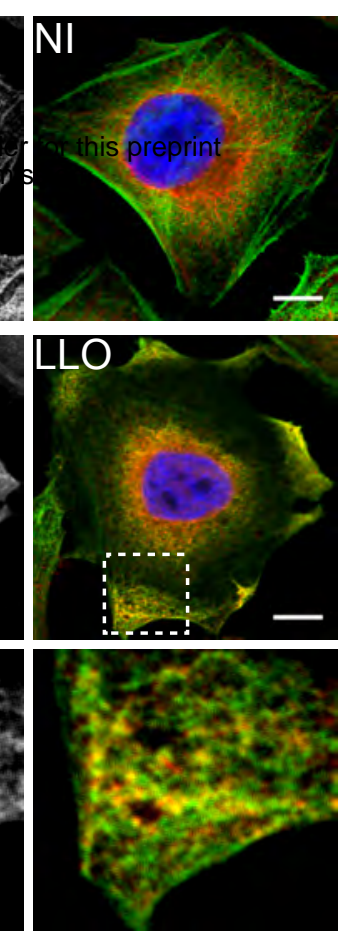

M

Src: WT CA KD

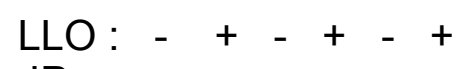

${ }_{\text {pTyr }}^{\mathrm{IP}}-\mathrm{NMHC} 2 \mathrm{~A}$

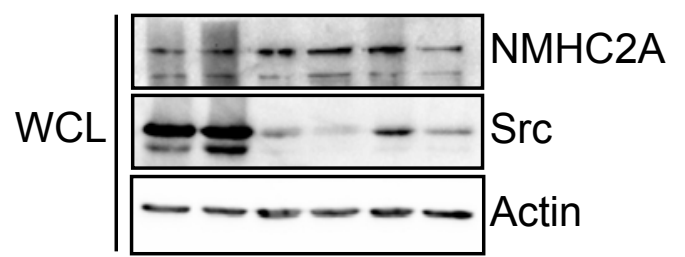

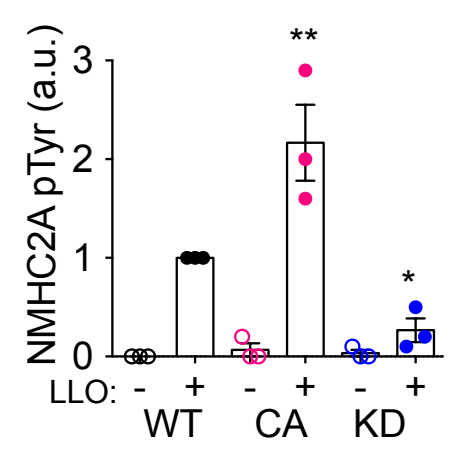




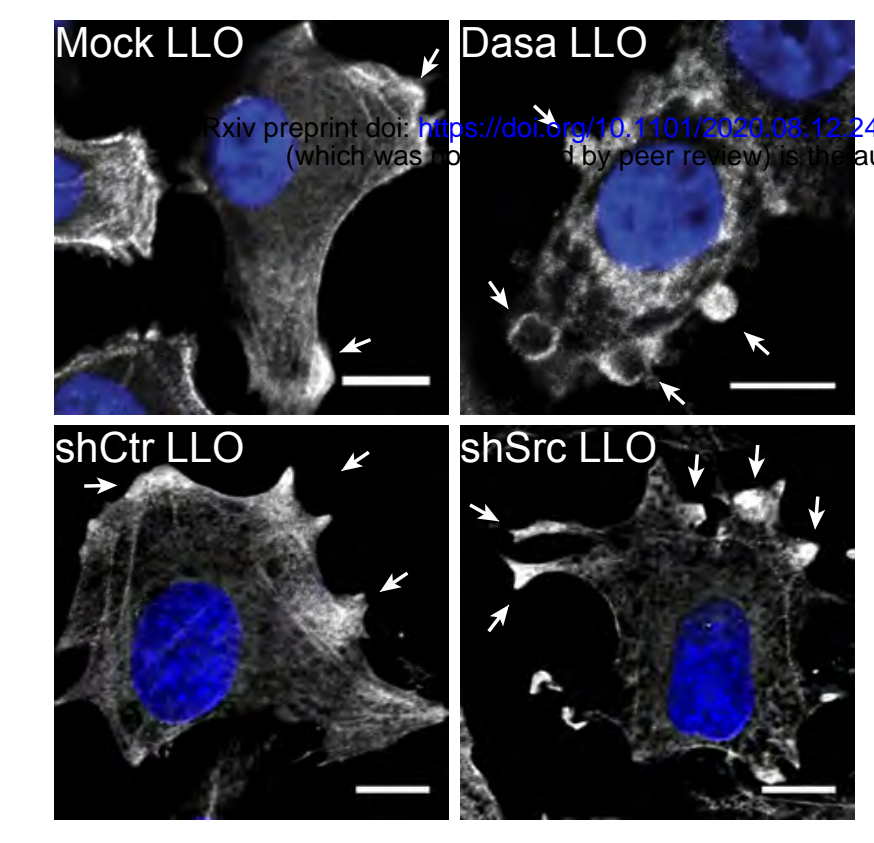

\section{B}

\section{C}

46090; this yersion posted August 13, 2020. The copyright holder for this preprint

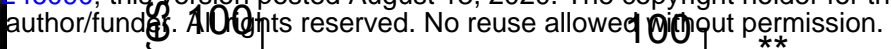

$\mathbf{F}$
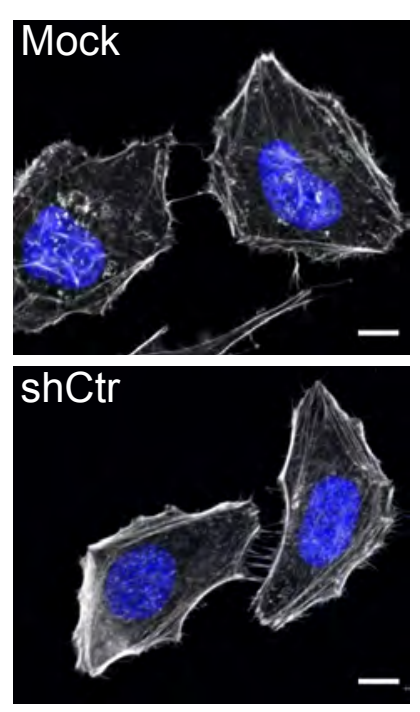

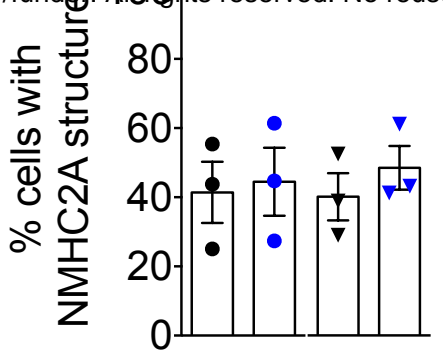

D

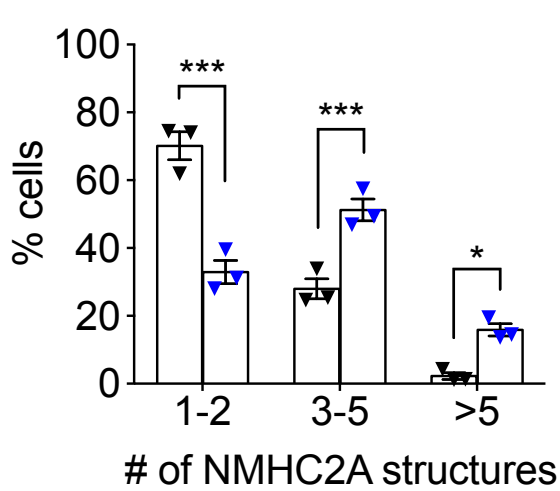

H

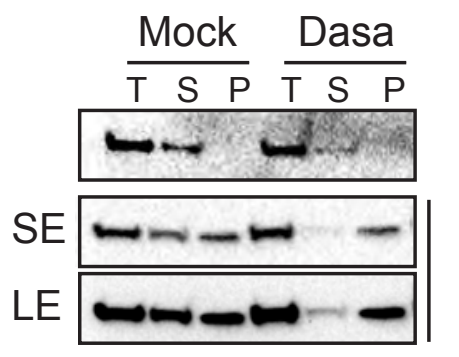

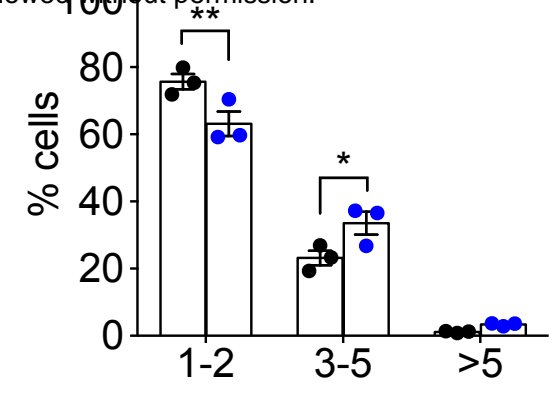

\# of NMHC2A structures

E

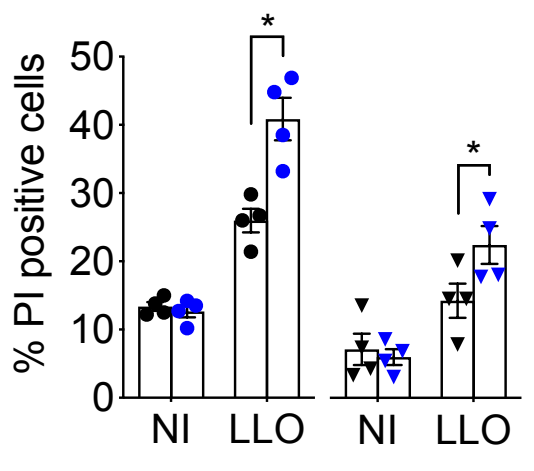

G
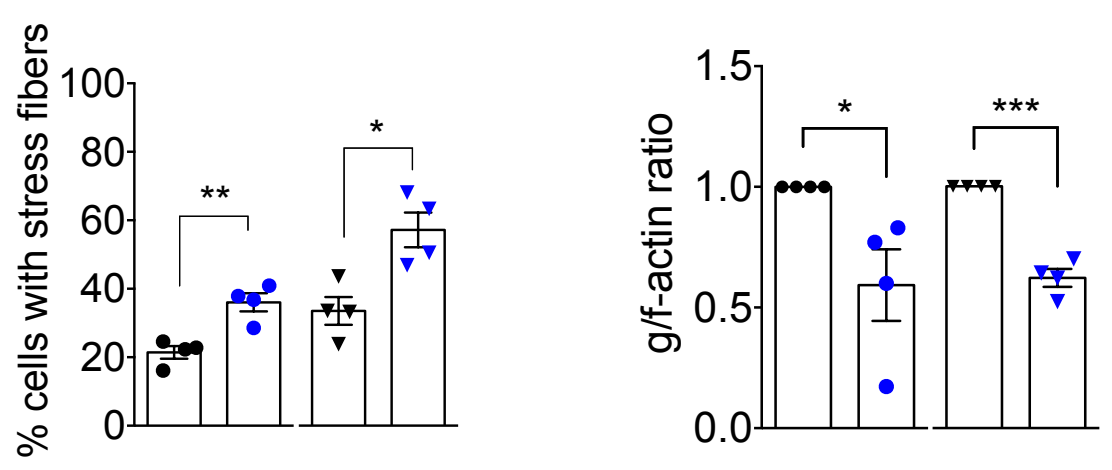
A

\section{- WT $\bullet \mathrm{Y} 158 \mathrm{E} \quad$ Y158F}
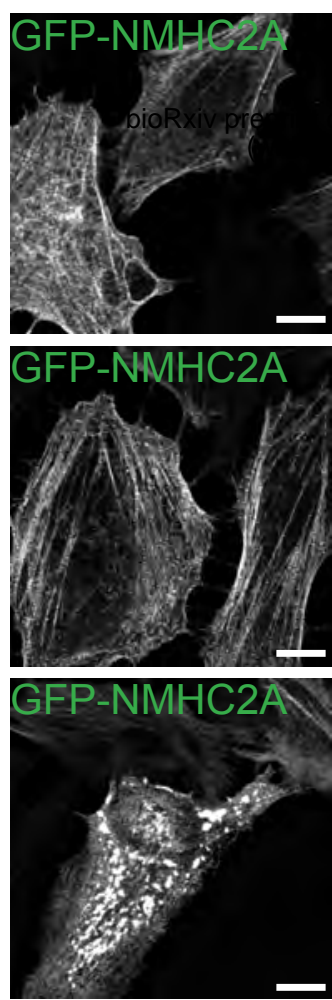

E

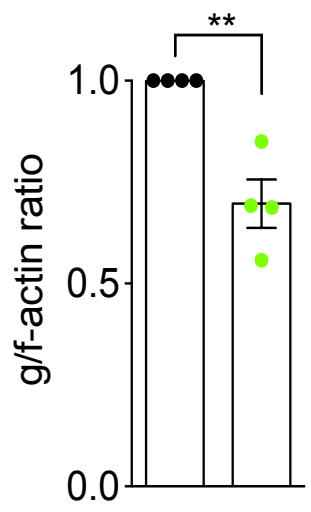

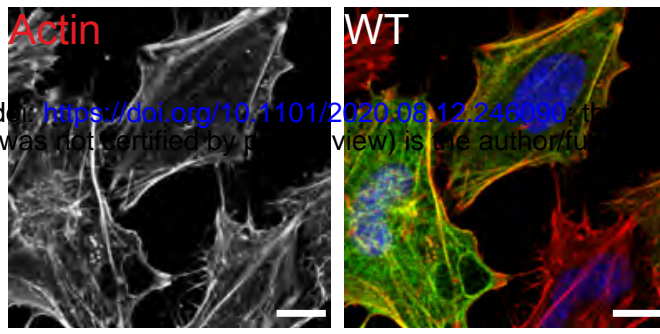
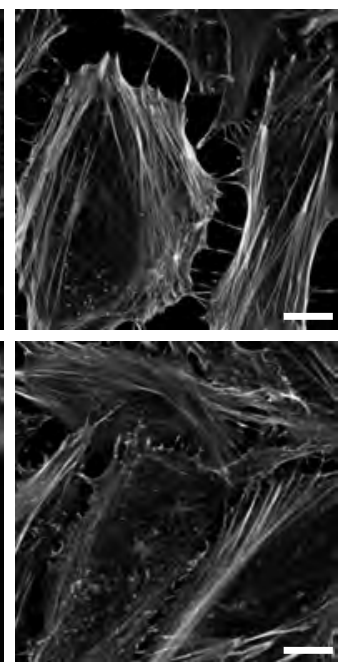

G

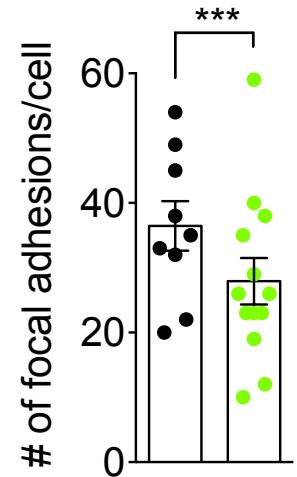

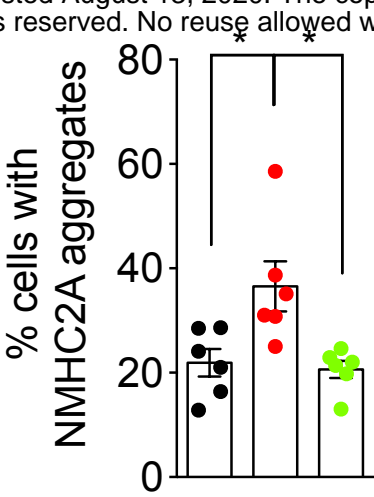

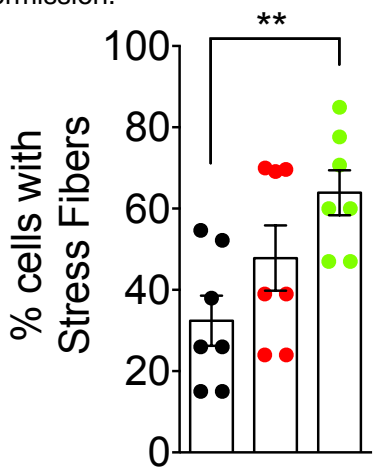

H

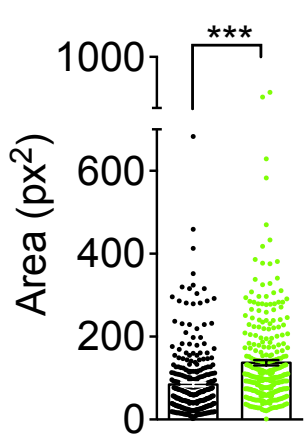

F
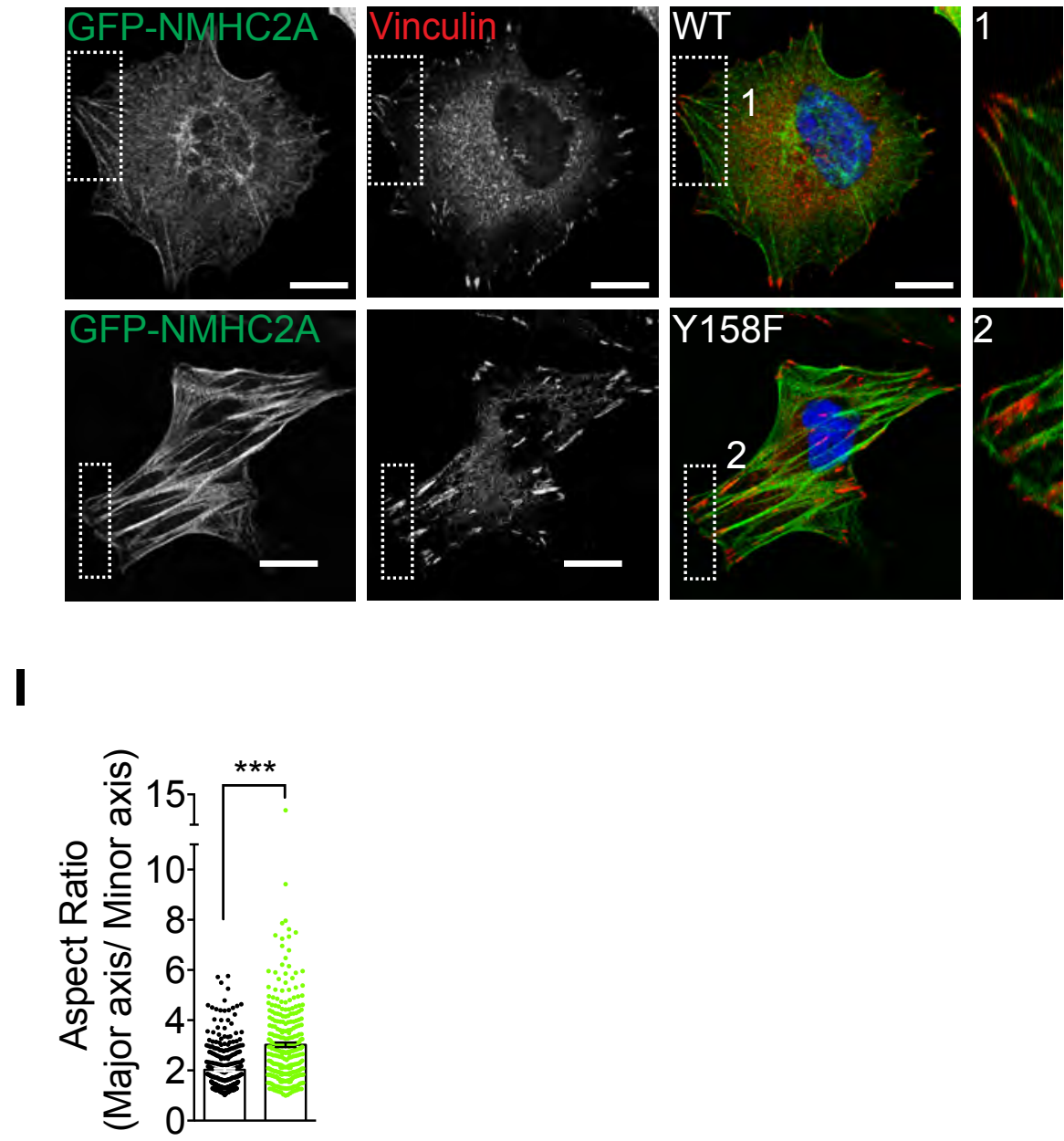


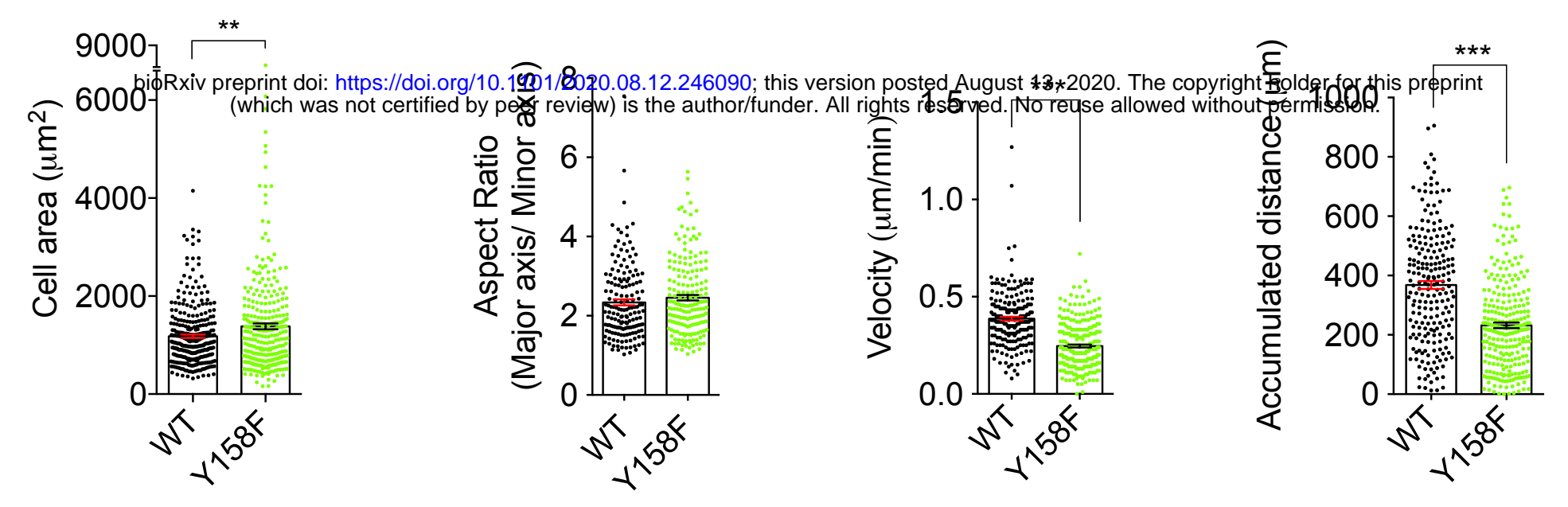


- WT • Y158E •Y Y158F

A

bioRxiv preprint doi: https://doi.org/10.1101/2020.08.12.246090; this version posted August 13, 2020. The copyright holder for this preprint 0.8 (which was not certified by peer review) is the author/funder. All rights reserved. No reuse allowed without permission.
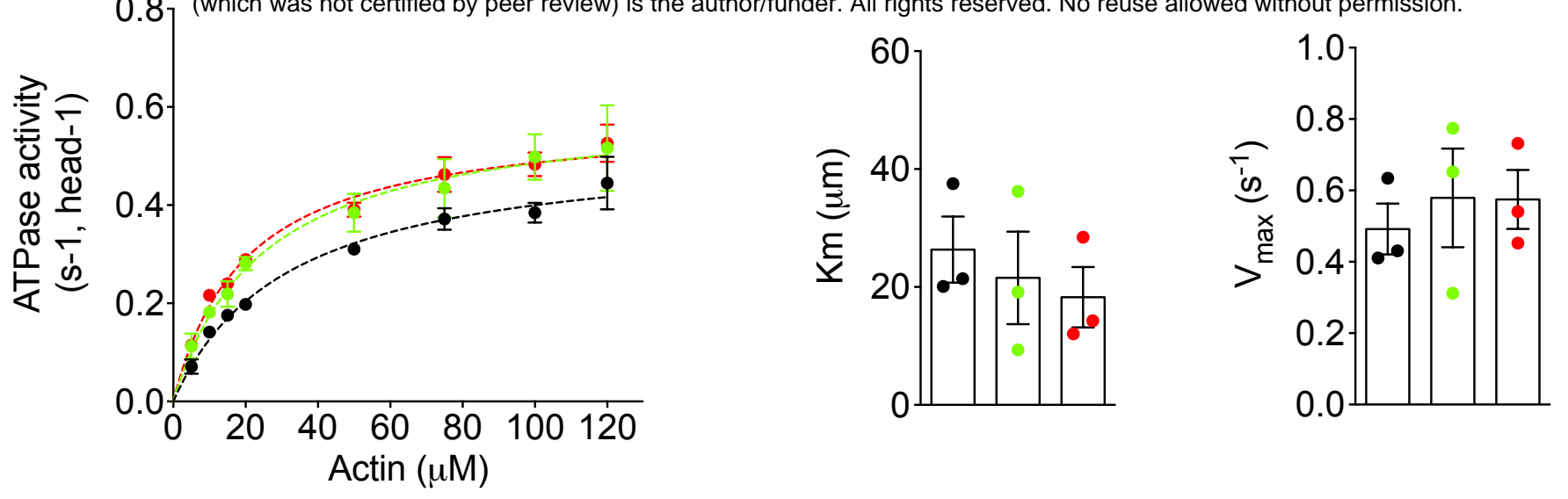

C

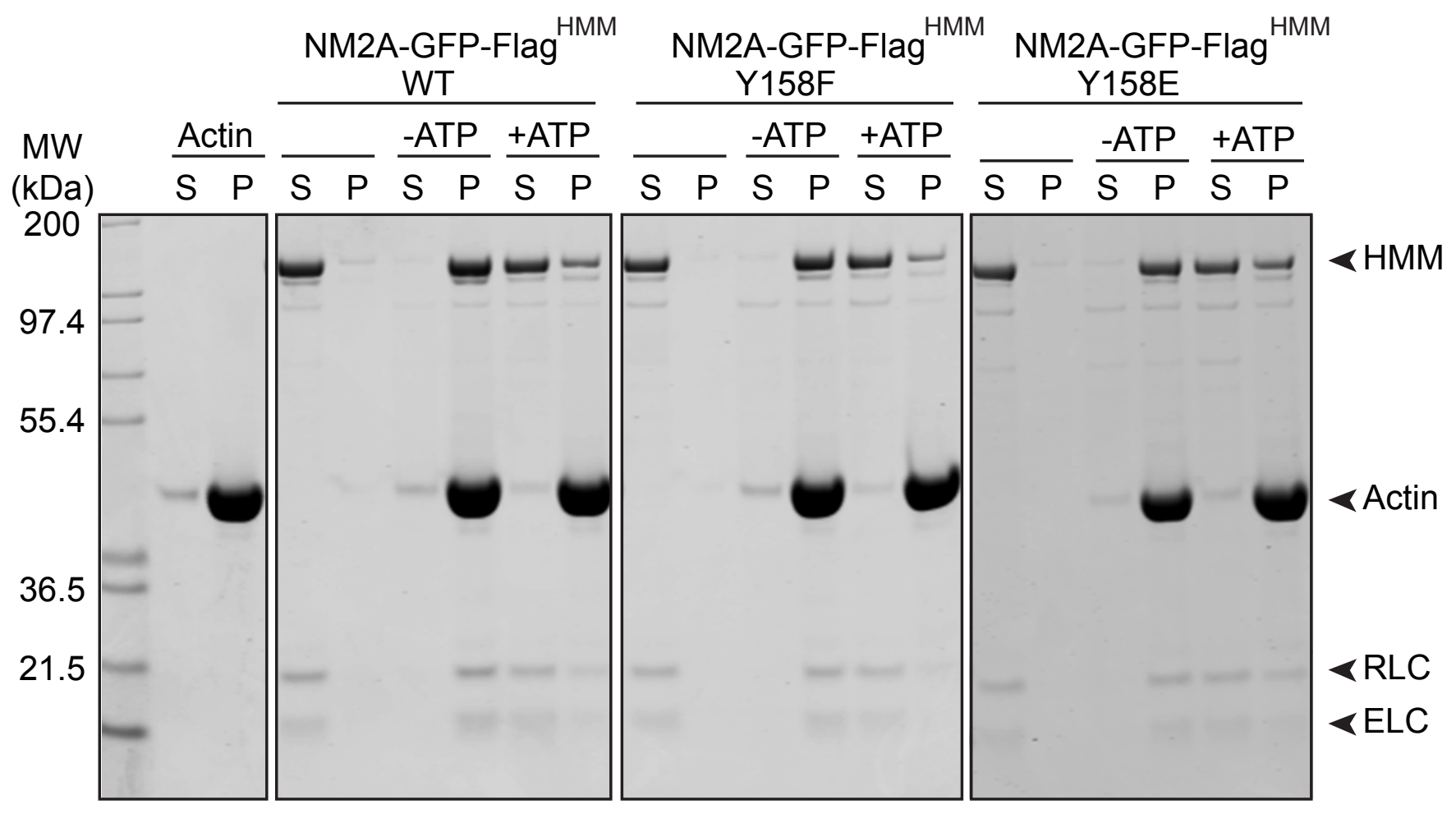

D $\mathbf{E}$
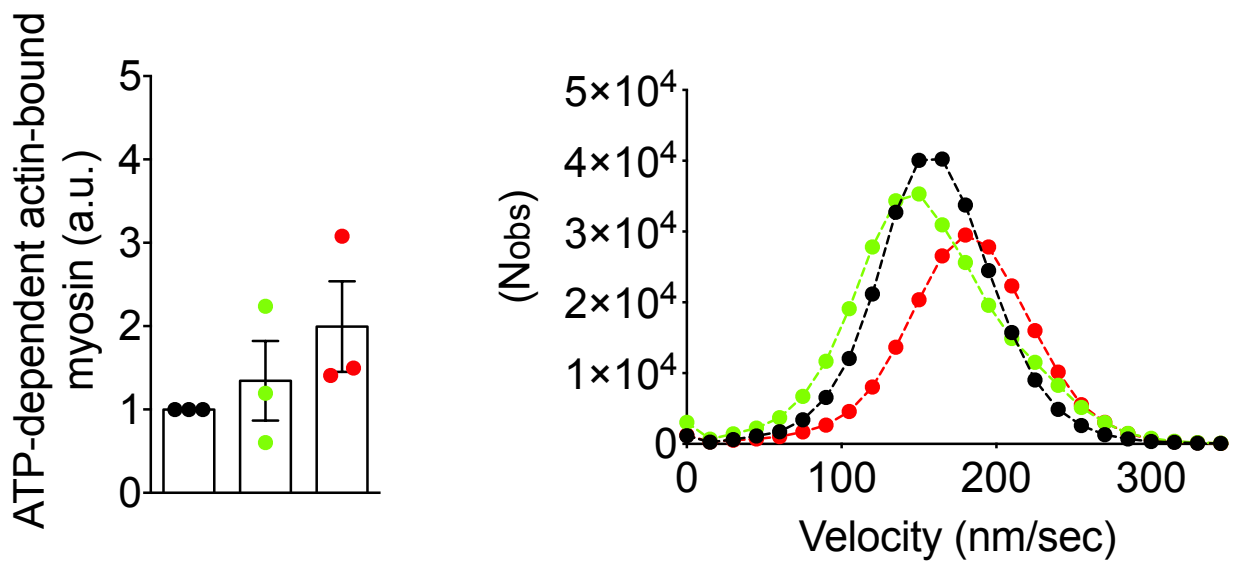


\section{GFP-NMHC2A}

1.0

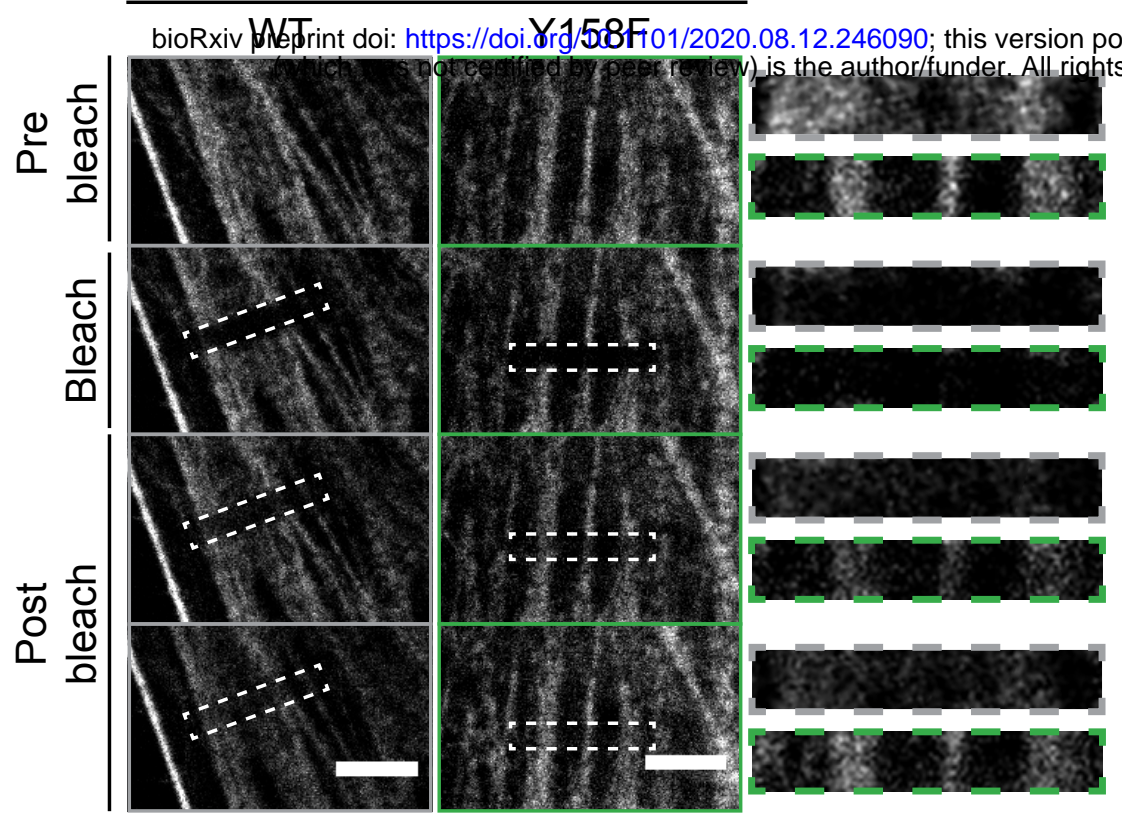

C

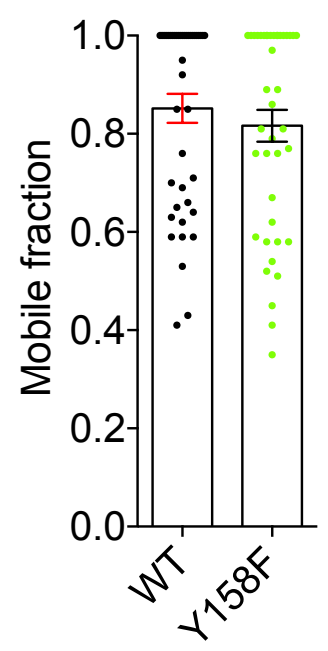

D

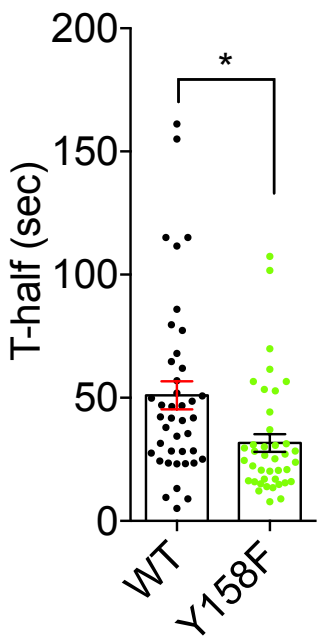

E

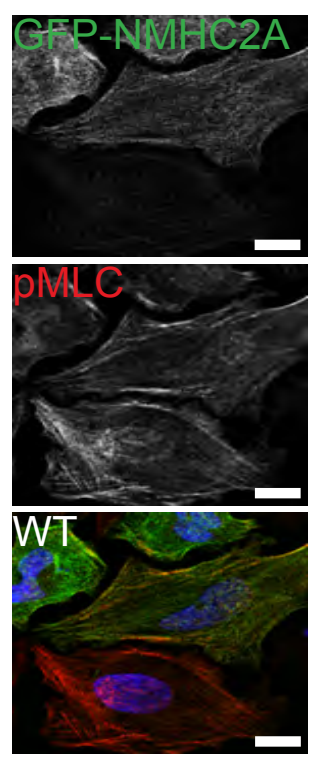

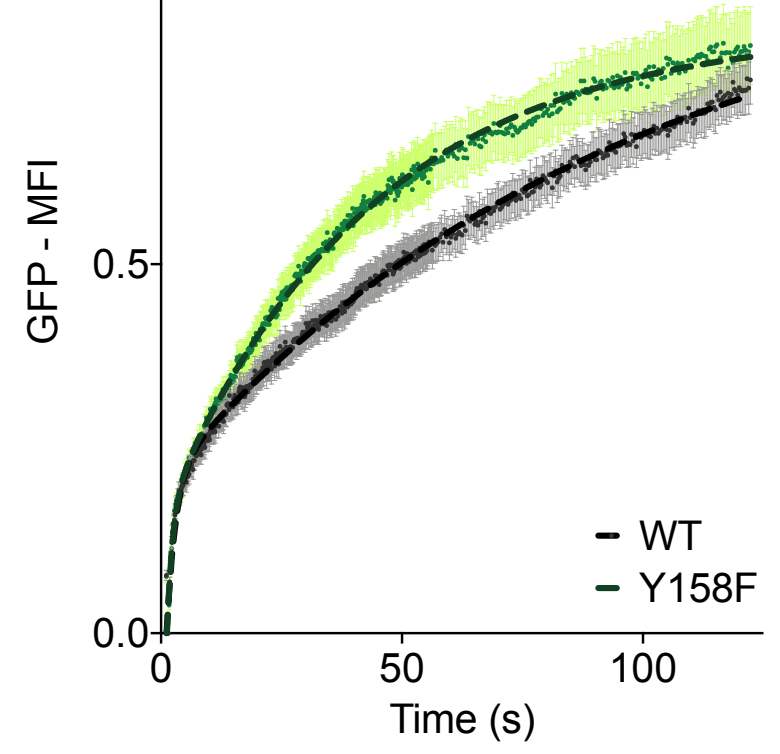

F
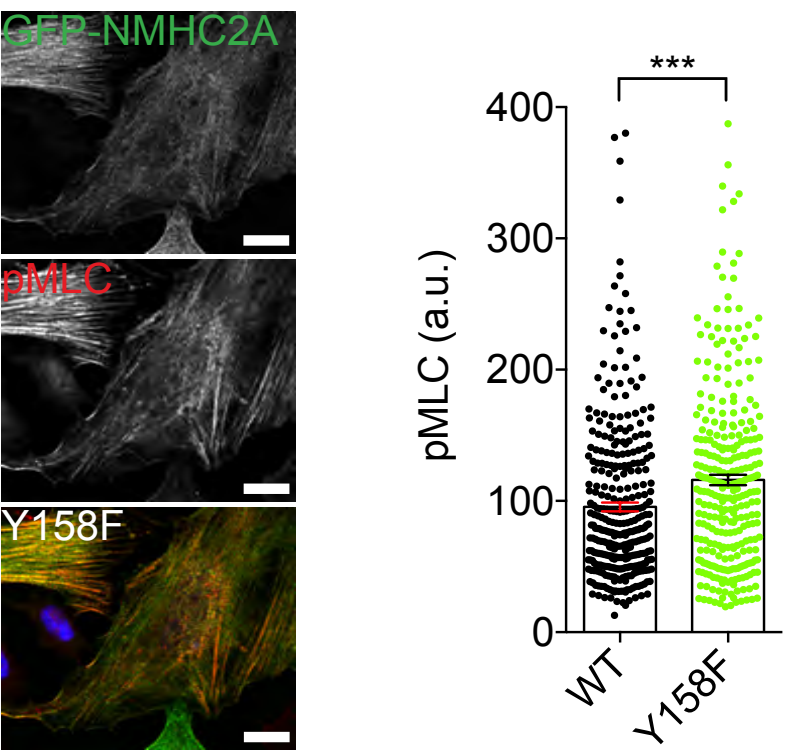
A

B

bioRxiv preprint doi: https://doi.org/10.1101/2020.08.12.246090; this version postegAugust 13, 2020. The copyright holder for this preprint
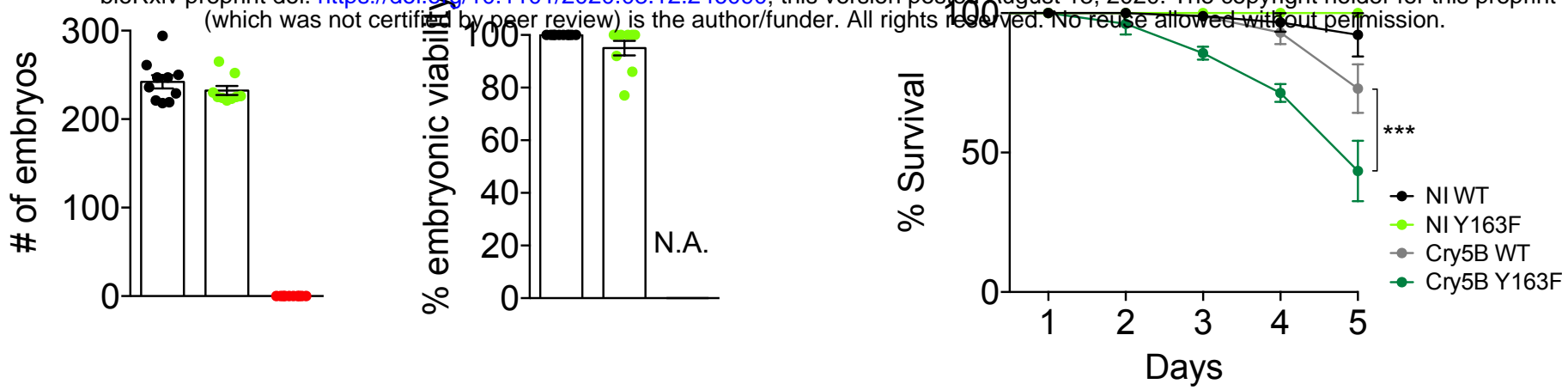

C

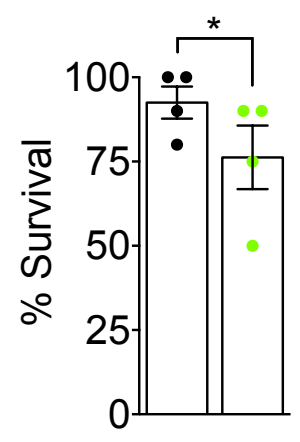

D

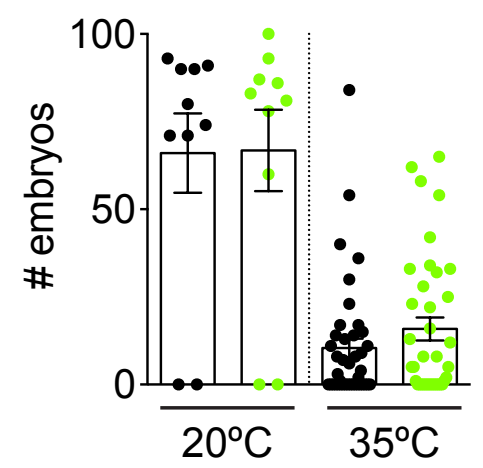

$\mathbf{E}$

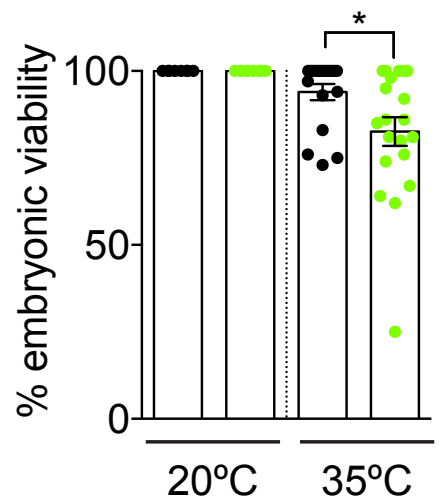

